PNL-10114

UC-

1400

\title{
The United States Department of Energy Office of Industrial Technology's Technology Benefits Recording System
}

K. R. Hughes

N. L. Moore

September 1994

Prepared for

the U.S. Department of Energy

under Contract DE-AC06-76RLO 1830

Pacific Northwest Laboratory

Richland, Washington 99352 


\section{DISCLAIMER}

This report was prepared as an account of work sponsored by an agency of the United States Government. Neither the United States Government nor any agency thereof, nor any of their employees, make any warranty, express or implied, or assumes any legal liability or responsibility for the accuracy, completeness, or usefulness of any information, apparatus, product, or process disclosed, or represents that its use would not infringe privately owned rights. Reference herein to any specific commercial product, process, or service by trade name, trademark, manufacturer, or otherwise does not necessarily constitute or imply its endorsement, recommendation, or favoring by the United States Government or any agency thereof. The views and opinions of authors expressed herein do not necessarily state or reflect those of the United States Government or any agency thereof. 


\section{DISCLAIMER}

\section{Portions of this document may be illegible in electronic image products. Images are produced from the best available original document.}




\section{Summary}

The U.S. Department of Energy (DOE) Office of Industrial Technology's (OIT's) Technology Benefits Recording System (TBRS) was developed by Pacific Northwest Laboratory (PNL). The TBRS is used to organize and maintain records of the benefits accrued from the use of technologies developed with the assistance of OIT.

OIT has had a sustained emphasis on technology deployment. While individual program managers have specific technology deployment goals for each of their ongoing programs, the Office has also established a separate Technology Deployment Division whose mission is to assist program managers and research and development partners commercialize technologies. As part of this effort, the Technology Deployment Division developed an energy-tracking task which has been performed by PNL since 1977 . The goal of the energy-tracking task is to accurately assess the energy savings impact of OIT-developed technologies.

In previous years, information on OIT-sponsored technologies existed in a variety of forms--first as a hardcopy, then electronically in several spreadsheet formats that existed in multiple software programs. The TBRS was created in 1993 for OIT and was based on information collected in all previous years from numerous industrial contacts, vendors, and plants that have installed OIT-sponsored technologies.

The TBRS contains information on technologies commercialized between 1977 and the present, as well as information on emerging technologies in the late development/early commercialization stage of the technology life cycle. For each technology, details on the number of units sold and the energy saved are available on a year-by-year basis. Information regarding environmental benefits, productivity and competitiveness benefits, or impact that the technology may have had on employment is also available. The system also contains background information on each technology included in the TBRS. All of the information contained in the TBRS is gathered through direct contact with either vendors of each technology or with end users of the technologies.

This report contains a detailed explanation of the OIT's TBRS. The contents of the TBRS are fully documented, and complete instructions for the program's use are included. The appendix contains the background files on each technology that appears in the system as they exist within the TBRS . 



\section{Contents}

Summary ......................... iii

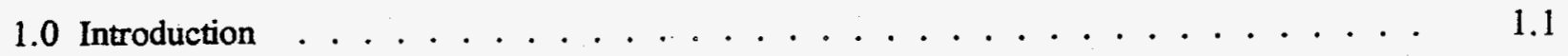

2.0 Background . . . . . . . . . . . . . . . . . . 2.1

2.1 What Is OIT's Technology Deployment Program? . . . . . . . . . . . . . 2.1

2.2 What Is the TBRS? . . . . . . . . . . . . . . . . . 2.1

2.3 Why Is Energy Savings Important? . . . . . . . . . . . . . . . . . . . 2.1

3.0 Technologies Included in the TBRS . . . . . . . . . . . . . . . . 3.1

3.1 Emerging Technologies . . . . . . . . . . . . . . . . . 3.1

3.2 Commercially Successful Technologies . . . . . . . . . . . . . . . . . . . 3.1

3.3 Data Collection Process . . . . . . . . . . . . . . . . . . . 3.3

3.4 Mature Technologies . . . . . . . . . . . . . . . . . . 3.4

4.0 Features of the TBRS . . . . . . . . . . . . . . . . 4.1

4.1 Summary Tables with Single-Year Synopses . . . . . . . . . . . . . . . . 4.1

4.1.1 Emerging Technologies Table . . . . . . . . . . . . . . . . . 4.1

4.1 .2 Commercially Successful Technologies Table . . . . . . . . . . . . . . . 4.3

4.1.3 Mature Technologies Table . . . . . . . . . . . . . . . 4.5

4.1.4 Savings Summary Sheet . . . . . . . . . . . . . . . . . . . 4.6

4.2 Technology-Specific Summary Tables . . . . . . . . . . . . . . . 4.6

4.3 Energy Savings Calculation Methodologies . . . . . . . . . . . . . . . 4.13

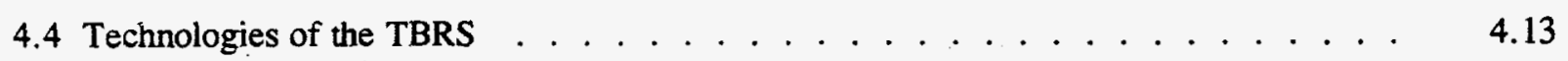

4.5 Miscellaneous Supporting Tables . . . . . . . . . . . . . . . . . . . 4.14 
5.0 Operation of the TBRS . . . . . . . . . . . . . . . 5.1

5.1 Getting Started . . . . . . . . . . . . . . . . . 5.1

5.1.1 Hardware and Software Requirements . . . . . . . . . . . . 5.1

5.1 .2 Installing the TBRS . . . . . . . . . . . . . . 5.1

5.1 .3 Creating an Icon for Activating the TBRS . . . . . . . . . . . 5.2

5.2 Using the TBRS . . . . . . . . . . . . . . . . . . . 5.2

5.2.1 Navigation Through the TBRS . . . . . . . . . . . . . . . 5.2

5.2.2 Changing the Current Date and Discount Rate . . . . . . . . . . . . 5.4

5.2.3 Accessing the Single-Year Summary Tables . . . . . . . . . . . . . 5.5

5.2.4 Accessing the Technology-Specific Files . . . . . . . . . . . . 5.5

5.2.5 Accessing the Calculation Methodology File . . . . . . . . . . . . 5.5

5.2.6 Qualitative Background Files . . . . . . . . . . . . . . . 5.6

5.2.7 The Cross-Reference File . . . . . . . . . . . . . . . . . . 5.6

5.2 .8 Printing . . . . . . . . . . . . . . . . . . . 5.6

6.0 The Future of TBRS . . . . . . . . . . . . . . . . . . 6.1

Appendix - Technology Background Files and Supporting Information . . . . . . . . . . . A. I 


\section{Figures}

3.1 The Technology Development and Commercialization Cycle and Location Within the TBRS

5.1 The Buttons and Their Associated Functions on the Technology Tracking Toolbar 


\section{Tables}

4.1 Emergining Technology Table $\ldots \ldots \ldots \ldots \ldots \ldots \ldots \ldots \ldots \ldots \ldots \ldots$

4.2 Estimated Energy Savings from Commercially Successful OIT Technologies, $1993 \ldots 4.4$

4.3 Estimated Energy Savings from Mature OIT Technologies, $1993 \ldots \ldots \ldots \ldots$. . . . . . 4.7

4.4 Technology Savings Summary Sheet $\ldots \ldots \ldots \ldots \ldots \ldots \ldots \ldots \ldots \ldots \ldots \ldots$

4.5 Sample Technology-Specific Summary Table $\ldots \ldots \ldots \ldots \ldots \ldots \ldots \ldots \ldots$ 


\subsection{Introduction}

The U.S. Department of Energy (DOE) Office of Industrial Technology's (OIT's) Technology Benefits Recording System (TBRS) was developed by Pacific Northwest Laboratory (PNL). The TBRS is used to organize and maintain records of the benefits accrued from the use of technologies developed with the assistance of OIT.

The TBRS contains information on technologies commercialized between 1977 and the present and on emerging technologies in the late development/early commercialization stage of the technology life cycle. For each technology, details on the number of units sold and the estimated energy saved are available on a year-by-year basis. Information regarding environmental benefits, productivity and competitiveness benefits, or impact that the technology may have had on employment is also available.

This report contains a detailed explanation of the OIT's TBRS. In Section 2.0, the OIT's Technology Deployment (TD) Program is explained. Examples of particular technologies included in the TBRS are given in Section 3.0. Section 4.0 describes features of the TBRS. The uses for and operation of the TBRS are outlined in Section 5.0. Section 6.0 provides a brief glimpse at the future for the TBRS. An appendix contains samples of technology background files and supporting information that are contained within the system. 


\subsection{Background}

The following information explains the OIT's TD Program, the TBRS, and the importance of energy savings.

\subsection{What Is OIT's Technology Deployment Program?}

The OIT is located within the Office of Energy Efficiency and Renewable Energy at DOE. OIT conducts research and development (R\&D) for and with U.S. Industry to improve energy efficiency, minimize waste production, and improve the competitive position of U.S. industry in the global marketplace.

A sustained emphasis on technology deployment has been maintained by OIT. While individual program managers have specific technology deployment goals for each of their ongoing programs, OIT has also established a separate TD Division with the mission of assisting program managers and R\&D partners to commercialize technologies. These $R \& D$ partners include industrial partners, universities, and the national laboratories, as well as other DOE offices and federal agencies.

\subsection{What Is the TBRS?}

In the past, information on OIT-sponsored technologies existed in a variety of forms--first, as a hard copy, then electronically in several different spreadsheet formats using multiple software programs. In 1993, the TBRS was created for OIT based upon information collected in all previous years from numerous industrial contacts, vendors, and plants that have installed OIT-sponsored technologies. Information exists in the TBRS on the estimated number of units sold and the estimated energy savings that have resulted from the use of these energy-efficient technologies. Supporting background information pertaining to each technology is available as well. The TBRS is updated annually and is available in Microsoft Excel $^{\mathrm{TM}}$ Version 5.0 for Windows ${ }^{\mathrm{TM}}$ as an application program. (NOTE: Users must have this software in order to access the TBRS database.)

\subsection{Why Is Energy Savings Important?}

The energy savings resulting from the successful commercialization of OIT-sponsored technologies are presented annually in a report to Congress. Energy savings is one metric of the success of OIT's TD Program. The number of plants and vendors that participate in TBRS is another indication of the widespread impact of these energy savings. The information collected from industry through this program can also be used by OIT as a tool for selecting technology transfer candidates to ensure congress that programmatic goals are being met. 


\subsection{Technologies Included in the TBRS}

The TBRS includes information on three primary categories: emerging technologies, commercially successful technologies, and mature technologies. What constitutes each of these categories, as well as what technologies are included in each category, is described in the following sections. Figure 1 describes the technology development and commercialization cycle, as well as the location of these technologies within the TBRS.

\subsection{Emerging Technologies}

Emerging technologies are generally identified by OIT program managers who suggest that an ongoing or recently completed research project should be included in the TD Program. Once a technology is identified, researchers from PNL assess the technology in terms of technical attributes, market readiness, market potential, and sales. Depending on the outcome of this effort, the technology is either placed in the emerging or the commercially successful technologies table. New technologies are usually placed in the emerging technology table. Technologies found in this table are expected to be added to the commercially successful technologies table in one or two years.

When placed on the emerging technology table, the technology may require additional technical development, it may be technically complete and have one or more demonstration units or pilot installations in operation, or it may have had a demonstration but has no full-scale commercial installation to date. Refer to Section 4.1.1 for a list of technologies currently in this category.

\subsection{Commercially Successful Technologies}

When a technology has at least one full-scale commercial unit installed that is operational, the technology is placed on the commercially successful technologies table. If the technology has an associated energy savings of less than 0.01 trillion Btu (cumulative or annually), an asterisk is placed in the associated column, indicating that energy savings to date are below that level. The primary benefit of some technologies that are part of OIT's TD Program is an environmental benefit, a process quality improvement, a positive impact on labor or an enhancement of (e.g., job creation) U.S. industrial competitiveness. Alternatively, some technologie have an energy savings in one area that is cancelled by an increase in energy consumption by another process associated with the technology (resulting in no net energy savings).

In such cases, the technology is still included in this table, but asterisks appear under the energy savings. The benefits of the technology would, in such a case, be described in the qualitative background on technologies portion of the TBRS (see Section 4.4). Section 4.1 .2 presents the table of commercially successful technologies. 


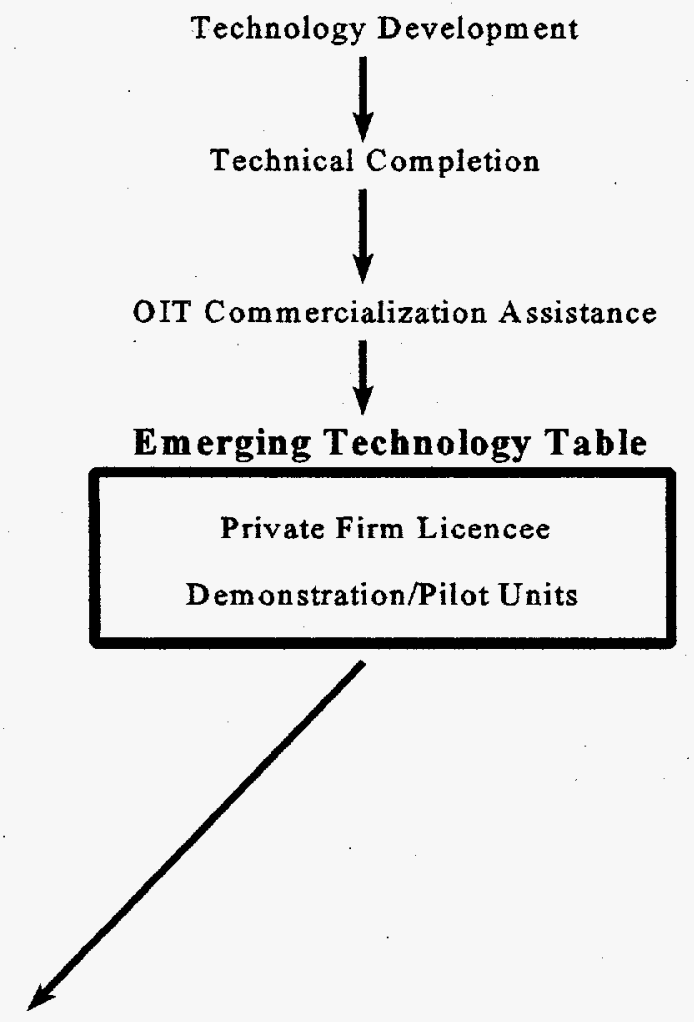

\section{Commercially Successful}

Technologies Table

Mature Technologies Table

Commercialized Units

\begin{tabular}{l}
1993 \\
1992 \\
1991 \\
1990 \\
1989 \\
1988 \\
1987 \\
1986 \\
1985 \\
1984 \\
1983 \\
1982 \\
1981 \\
1980 \\
1979 \\
1978 \\
1977 \\
\hline
\end{tabular}

\begin{tabular}{|c|} 
Mature Units \\
$\sim 1982$ \\
$\sim 1981$ \\
$\sim 1980$ \\
-1979 \\
-1978 \\
-1977
\end{tabular}

Figure 3.1. The Technology Development and Commercialization Cycle and Location Within the TBRS 


\subsection{Data Collection Process}

All of the information contained in the TBRS is gathered through direct contact with either vendors of each technology, or with end users of the technologies (e.g., plants). For new technologies, initial industry contacts are provided by DOE program managers. Calculation methodologies for each technology are developed by PNL in collaboration with the industry contacts. Once developed, these methodologies are reviewed and amended, if necessary, by the appropriate DOE program manager.

The industry contact is consulted each year regarding how many units of the technology were added, how many units were decommissioned, what type of units were installed (if multiple types exist), and what the operating schedules are for that year. A number of general questions are also asked pertaining to other benefits of the technology and to market-related issues. The questions that are commonly asked are listed below:

- How many units are currently operating? (Verify against previously recorded information.)

- How many new units have been installed since September of the previous year? What are their sizes and locations?

- How many units have been decommissioned since September of the previous year? Which units were these (site, location, size)?

- How many units have been sold overseas? Where? When? What is their capacity?

- Of these overseas units, how many are operating? Which ones?

- What environmental benefits does the technology have?

- What quality improvements does the technology result in (e.g. process quality, output product qualtiy etc)?

- What productivity improvements (increased throughput, increased yield) does the technology result in?

- Has the use of the technology had any impact on employment that you are aware of (e.g., are jobs created/terminated as a result of the use of the technology)?

- What difficulties have you experienced in selling the technology? What might be done to overcome these barriers?

- What have been the strongest selling points of the technology? 


\subsection{Mature Technologies}

Energy savings that appear on the commercially successful technologies table are claimed by OIT as a direct impact of the TD Program. It is assumed that this program resulted in an acceleration of the development and commercialization of a given energy-efficient technology. Without this program, such a technology may still have been developed; however, the development (it is assumed) and subsequent commercialization of the technology would have occurred at a later date than would have occurred under the influence of the OIT TD Program. The goal of the TD Program is to accelerate the commercialization of energy-efficient technologies over what would have occurred in the marketplace without the influence of the TD Program.

Energy savings from technologies that are participants in the TD Program are claimed for a ten-year window. Energy savings from units installed more than ten years ago (with respect to the year of installation and the year selected as the "current" year in the system--see Section 4.0) are not counted in the commercially successful technologies table. Instead, savings from these units are accumulated in the mature technologies table, which is presented in Section 4.1.3. 


\subsection{Features of the TBRS}

The TBRS contains four primary sets of information on OIT technologies included in the TD Program, as well as miscellaneous supporting tables. This information is contained in the following sections:

- Section 4.1: summary tables containing single-year synopses of energy savings, dollar values associated with the savings, and units operating across all technologies (the emerging technologies table falls into this category)

- Section 4.2: technology-specific tables containing detailed information on energy savings and units in operation for a single technology across multiple years

- Section 4.3: methodologies for calculating energy savings (containing assumptions and sample calculations)

- Section 4.4: qualitative background information on each technology, including a description of the technology, its benefits, and a diagram of the technology

- Section 4.5: miscellaneous supporting tables.

\subsection{Summary Tables with Single-Year Synopses}

The TBRS contains three main summary tables with information covering multiple technologies: the emerging technologies table, the commercially successful technologies table, and the mature technologies table. Each of these tables is described in the following sections. For a description of which technologies appear in these tables and why, please refer to Section 3.0. It is important to note that the figures contained in these tables (under both unit and energy savings) are for the "current year." The current year is set by the TBRS user and is based on what year the user has selected through the Current Year Dialog box. Setting the current year is discussed in Section 5.0 .

\subsubsection{Emerging Technologies Table}

As described in Section 3.1, the emerging technologies table contains a list of those technologies expected to be added to the commercially successful technologies table within one or two years. In addition to the name of the technology, this table contains the status of the technology (whether the technology has been fully developed, is in a demonstration stage, is awaiting commercial installation, etc.). The technologies included on this table (as of 1993) appear in Table 4.1. 
Table 4.1. Emerging Technology Table

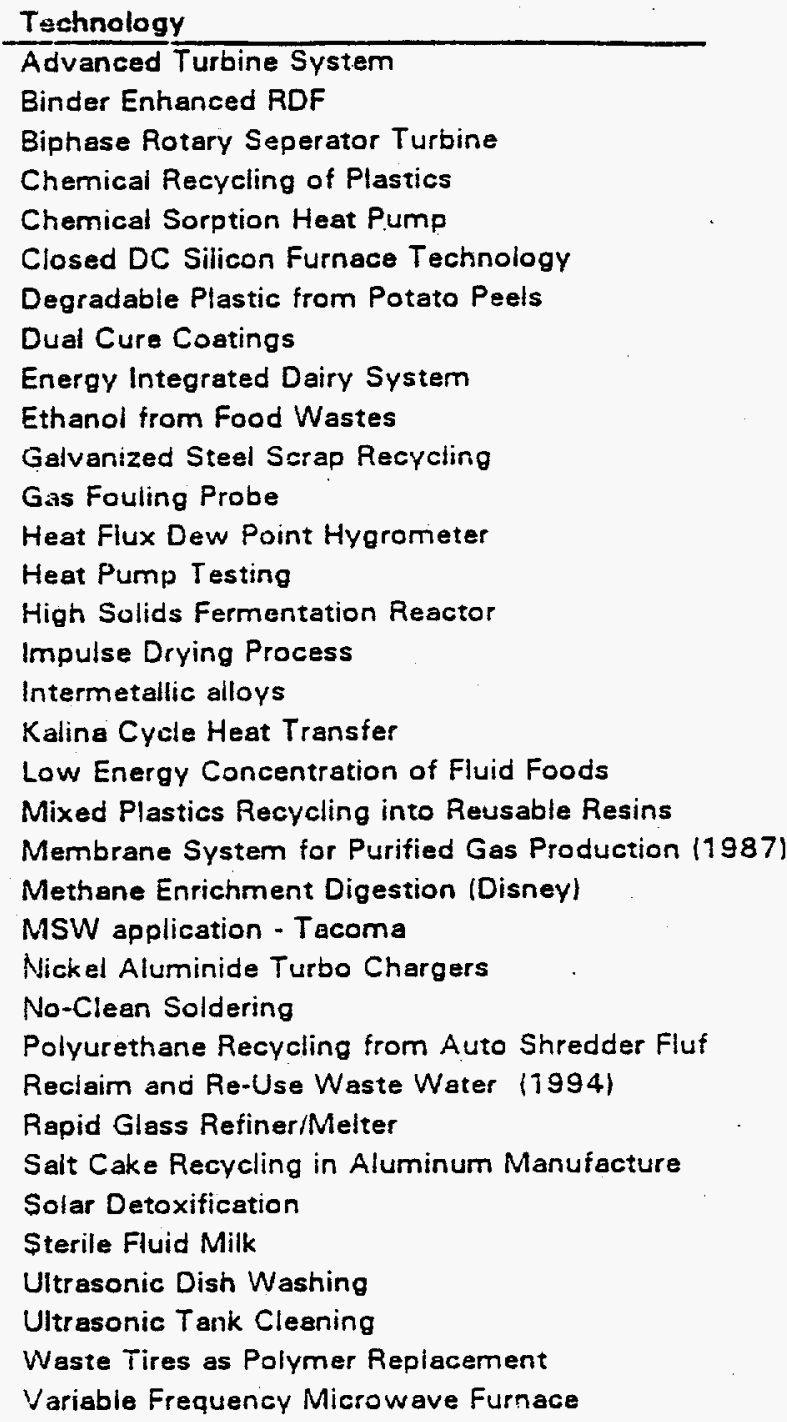




\subsubsection{Commercially Successful Technologies Table}

The commercially successful technologies table contains a variety of fields, most of which relate to the number of units commercialized and the energy savings associated with these commercialized units. As described in Section 3.2, this table contains information on OIT TD technologies that have sold at least one unit. The specific fields within this table are summarized below.

- Technology and Approximate First Year of Installation. The name of the technology and the year that the first commercial-size unit went into operation.

- Total Number of Units Installed. The total number of units that have been installed since the technology was commercialized.

- Total Number of Units Decommissioned. The total number of units that have been taken out of service (are not saving energy) to date.

- Total Number of Units Moved to Table 4.2. As described in Section 3.3, units of a particular technology (and their associated energy savings) that are older than ten years are transferred to the mature technologies table. This column contains the total number of units that have been transferred to the mature technologies table.

- Total Number of Units Counted in Energy Savings. The total number of units that are in operation at the given date. This number equals the total number of units installed minus the total number of units decommissioned minus the total number of units transferred to Table 4.2 (the mature technologies table).

- Estimated Energy Savings. The annual estimated energy saving resulting from the use of the units appearing in the total number of units operating. Energy savings from units transferred to the mature technologies table (referenced in the commercially successful technologies table as Table 4.2) are not included in this figure.

- Current Year Energy Savings Transferred to Table 4.2. The quantity of energy savings associated with units older than ten years that have been transferred to the mature technologies table (referred to as Table 4.2 in the TBRS) during the current year.

- Cumulative Energy Savings Transferred to Table 4.2. The total amount of energy savings transferred over the years to the mature technologies table (savings associated with the total number of units transferred to the mature technologies table).

- Energy Savings Rate. The energy savings rate column contains energy savings figures for the current year that have been adjusted to account for any units that may have been installed in the current year and have operated for only a fraction of the year. The energy savings rate adjusts 
Table 4.2. Estimated Energy Savings from Commercially Successful OIT Technologies, 1993

\begin{tabular}{|c|c|c|c|c|c|c|}
\hline Technology and Approximate First Vear of linstallotion & $\begin{array}{l}\text { Total Number of } \\
\text { Units Imstalled }\end{array}$ & $\begin{array}{l}\text { Total Number of } \\
\text { Units Counted in } \\
\text { Energy Savings }\end{array}$ & $\begin{array}{c}\text { Estimated } \\
\text { Energy Savings } \\
\text { (10E12 Bful }\end{array}$ & $\begin{array}{c}\text { Energy } \\
\text { Savings Rate } \\
\text { (1OE12 Btul) }\end{array}$ & $\begin{array}{c}\text { Curmulative Savings } \\
\text { (10E12 Btu! }\end{array}$ & $\begin{array}{l}\text { Type of Fual } \\
\text { Saved }\end{array}$ \\
\hline Biomase Grain Diyor $(19 \overline{1} \overline{01}$ & 31 & 11 & 0.08 & 0.08 & $0 . \overline{84}$ & $E, P$ \\
\hline Catnlytic Roactor $(1982)$ & 32 & $31^{\circ}$ & 2.57 & 4.65 & 5.01 & RG \\
\hline Cement Particlo Sizo Classiflum $(1984)$ & 215 & 215 & 2.16 & 3.31 & 8.55 & $\mathbf{E}$ \\
\hline Chansical Sopnration by Fluid Extriction 11991 ) & 2 & 2 & 0.00 & 0.00 & 0.01 & $\mathbf{F}$ \\
\hline Coponeration-Coat-Firad Steam Turhino (1982) & 19 & 18 & 12.90 & 12.90 & 68.56 & c \\
\hline Cogeneration-Slow $S_{p}$ pod Diosind $(1983)$ & 4 & $\mathbf{0}$ & 0.00 & 0.00 & 17.68 & E,F \\
\hline Computer Contrulled Ovan (1982). & 15 & 12 & 2.28 & 2.28 & 21.78 & NG \\
\hline EADCs $(1976)$ & 4463 & 3397 & 8.84 & B.64 & 72.52 & E.F.NG \\
\hline EnorgV Ellicient Canning (1980) & 118 & 68 & 0.23 & 0.24 & 2.21 & G \\
\hline Higl Elficioncy Wold Unil (1983) & 44,345 & 43345 & 2.73 & 2.87 & 10.76 & $\mathbf{E}$ \\
\hline Hyperlittration-Food (1990) & 14 & 11 & 0.76 & 0.76 & 2.64 & E \\
\hline Hyporfiltration-Toxtilos (1983) & 10 & 7 & 0.19 & 0.19 & 0.69 & c \\
\hline Iluprovad Diasol Enginos (1992) & 579,800 & 579,800 & 48.52 & 48.52 & 97.05 & $\mathbf{F}$ \\
\hline Irrigation Systoms (1981) & 15,000 & 7,500 & 3.58 & $\mathbf{3 . 5 8}$ & 42.44 & E,F,NG \\
\hline Mombrane Syatem for Purrilioul Gas Produtetion (1987) & 47 & 47 & N/A & N/A & M/A & N/A \\
\hline Mothanal Racovery Procoss (1993) & 1 & 1 & 0.04 & 0.07 & 0.06 & NG \\
\hline Nisogan-Mouluanol Carturization (1978) & 2251 & 985 & 0.44 & 0.44 & 9.79 & NG \\
\hline No-Clean Soldering Process \{1990\} & 1 & 1 & 0.00 & 0.01 & 0.01 & E \\
\hline PET Bottlo Separator (1988) & $i$ & 0 & 0.00 & 0.00 & 1.21 & $\mathrm{Ch}$ \\
\hline Plating Waste Concentralor 119821 . & 78 & 63 & 0.67 & 0.66 & 1.46 & F,NG \\
\hline Rechiperators (G IE) (198\|) & 1137 & 647 & 1.29 & 1.29 & 19.85 & F. NG \\
\hline Reverse Brayton Cycle Solvall Rucovary (1989) & 7 & 6 & 0.26 & 0.40 & 0.77 & Ch, NG \\
\hline Slot Forge Furnaco/Ancupurator $(1978)$ & 38 & 32 & 1.05 & 1.20 & 9.71 & F.NG \\
\hline Solvant Recovary from Ellluant Straans (1990) & 19 & 19 & 0.19 & 0.32 & 0.27 & Cl, \\
\hline Wasto Enorgy Rocovory 11 1990) & 1 & 1 & 3.41 & 3.41 & 13.63 & $\mathbf{F}$ \\
\hline Total & 647,649 & 638.198 & 91.87 & 95.82 & 407.50 & \\
\hline
\end{tabular}

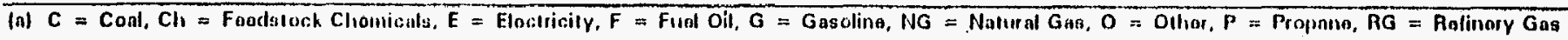


the annual energy savings figure for those units instailed in the current year by presenting an energy savings figure that would have occurred had said units operated for a full year.

- Cumulative Savings. The cumulative savings figure contains the total energy savings of all units for the total time the technology has been in operation. Note that the cumulative figure shown reflects savings only from those units included in this table up to the current year. The cumulative figure contained in the mature technologies table (described below) reflects savings for all units accounted for in that table. Hence, the grand total of energy savings for a technology is the sum of the cumulative savings reported in both tables. The cumulative savings in the commercially successful technologies table reflects the total energy savings claimed to be a result of the OIT TD Program. Yearly and cumulative saving from units older than ten years are not claimed by the OIT TD program and appear in the mature technologies table.

- Type of Fuel Saved. The types of fuel that are saved through the use of this technology are listed in this column by a code letter that is keyed to explanatory text at the bottom of the table.

- Coal - Refinery Gas. The columns with the heading "Coal" through the column with the heading "Refinery Gas" provide the percentage of each particular type of fuel saved by those technologies that save more than one type of fuel. These figures are estimated based on the type of fuel that would have been consumed by the technologies displaced by the OIT TD technology.

The contents of the commercially successful technologies table, as of 1993, appear in Table 4.2.

\subsubsection{Mature Technologies Table}

As described in Section 3.3, the mature technologies table contains information on units or installations of particular technologies that are ten or more years old. As units reach the ten-year point, the units and their associated energy savings are transferred from the commercially successful technologies table to the mature technologies table. When all of the units of a particular technology are transferred to the mature technologies table, the technology name is removed from the commercially successful technologies table. The following fields within this table are described below:

- Technology and Approximate First Year of Installation. The name of the technology and the year that the first commercial-size unit went into operation.

- Number of Mature Units. The units appearing here are those installed ten or more years ago (relative to the currently selected year--see Section 4.1 above).

- Type of Fuel Saved. The types of fuel that are saved through the use of this technology are listed in this column by a code letter that is keyed to explanatory text at the bottom of the table. 
Table 4.3 illustrates a sample of the mature technologies table, as of 1993.

\subsubsection{Savings Summary Sheet}

The savings summary sheet contains economic information associated with both commercially successful and mature technologies. The table contains the total DOE investment in the technology in dollars, the total dollar value associated with the energy savings from the technology, and the net of these two quantities. The dollar values for energy savings are determined by summing (across the years the technology saved energy) the present value of the product of the technology's energy savings for a given year and the cost of the fuel (or fuels) saved by the technology in that given year. The present values are found using the discount rate that appears at the top of the table and the current year also found at the top of the table (for information on how to set the discount rate and the current year, see Section 5.0). An example of this table for 1993 appears in Table 4.4 below.

\subsection{Technology-Specific Summary Tables}

The second major category of information contained in the TBRS is the technology-specific tables containing unit and energy savings information from each year that the technology has had commercial-scale units in operation. Each of these sheets exists in a common format. The specific information contained in each table is described below.

The name of the technology appears at the beginning of each table. This is followed by a section (which is displayed by pressing the appropriate button; see Section 5.0 for a description of how this information is accessed) containing the names of the industrial contacts whom PNL annually interacts with to collect the information contained in the TBRS. Typically, the contact's name, address, and phone and FAX numbers appear. Below and to the right of this information appears detailed information on energy savings on a plant-by-plant basis (based upon the year each plant went into operation as well as the energy savings that unit's operation in the year of installation and each subsequent year). In many cases, the PNL contact for a particular technology may be a vendor rather than an end user of the technology. In these cases, the units sold by that vendor (and their resulting energy savings) appear.

The next section of technology-specific tables contains a table devoted exclusively to the number of units of the technology that have sold. The rows of this table contain the following information for every year the technology has been in operation:

- Units Installed in Given Year. The number of units installed in a particular year (each year is a column heading in the table).

- Total Units Installed to Date. The total number of units of the technology installed up to the date of the column in which the number appears. 
Table 4.3. Estimated Energy Savings from Mature OIT Technologies, 1993

\begin{tabular}{|c|c|c|c|}
\hline Technology and Approximate First Year of Installation & $\begin{array}{c}\text { Number of } \\
\text { Mature Units }\end{array}$ & $\begin{array}{c}\text { Cumulative } \\
\text { Savings for Unizs } \\
\text { No Longer Tracked } \\
(10 E 12 \text { Btu })^{*}\end{array}$ & $\begin{array}{c}\text { Type of } \\
\text { Fuel Saved } \\
\text { (a) }\end{array}$ \\
\hline Biomass Grain Dryer $(1980)$ & 20 & 0.06 & $E . P$ \\
\hline Catalytic Reactor (1982) & 1 & 0.05 & RG \\
\hline Cogeneration-Coal-Fired Steam Turbine (1982). & 1 & 0.68 & C \\
\hline Coil Coating $(1977)$ & 25 & 35.20 & NG \\
\hline Combination Grain Drying (1980) & 2.500 & 7.30 & $P$ \\
\hline Computer Controlled Oven (1982) & 3 & 0.53 & NG \\
\hline Cupola Stack Air Injeczion (1981) & 2 & 0.08 & NG \\
\hline Dye Bath Reuse (1979) & 69 & 2.00 & NG \\
\hline EADCs $(1976)$ & 1066 & 1.75 & $E, F, N G, O$ \\
\hline Energy Efficient Canning (1980) & 50 & 0.11 & G \\
\hline FBWHRS (Aerojet) (7984) & 1 & 0.03 & $F, N G$ \\
\hline Foam Processing (1980) & (c) & 11.40 & NG \\
\hline Heat Exchanger-Dryer & 3 & 0.79 & NG \\
\hline HTBDR (AiResearch) (1979) & 1 & (b) & NG \\
\hline HTBDR (Babcock and Wilcox) (1981) & 1 & 0.02 & NG \\
\hline Humidity Sensor (Optical) (1988) & 2 & 0.02 & NG \\
\hline Irrigation Systems (1981) & 7,500 & 2.15 & E.F.NG \\
\hline Membrane Separation of Sweetners & $i$ & (b) & E.NG \\
\hline Nitrogen-Methanol Carburization (1978) & 1285 & 0.52 & NG \\
\hline ORC Bottoming Unit (1981) & 7 & 0.50 & $E$ \\
\hline Pipe Cross Reactor $(1976)$ & 31 & 2.60 & NG \\
\hline Plating Waste Concentrator $(1982\}$ & 2 & 0.01 & F,NG \\
\hline Recuperators (GTE) (1981) & 490 & 0.73 & F,NG \\
\hline Recuperators (AiResearch) (1981) & 106 & 4.50 & NG \\
\hline Slot Forge Furnace/Recuperator (1978) & 4 & 0.12 & $F, N G$ \\
\hline Waste Atactic Polyproplene to Fuel (1980) & 1 & 0.50 & $F, N G$ \\
\hline Workshops (Boiler) (1977) & $10(d)$ & 42.20 & F.NG \\
\hline Total & & 113.85 & \\
\hline
\end{tabular}

-Units and savings shown here are for unirs not sppearing in Tobie 1. Sevings are for units that are either older than ten years of oge or ere not oporating.

The cumulative sovings have been limited to savings dunng the unit's operating period. but not to exceed 10 years of sevine on the basis that the units would have been insealled by the 10th year without the Department of Enorgy's Acceieretion Program for impiementing the tecinnology. 
Table 4.4. Technology Savings Summary Sheet

Interest Bate:

Current Year:

$0 \%$

1993

Techinology/Fuel Type

Biomass Grain Dryer

Catalytic Reactor

Cement Particle Size Classifier

Chemical Seperation by Fluil Extraction

Cogeneration: Coal Fired Steam Tubline

Cogeneration: Slow Spted Diesel

Compuler Controlled Oven

EADCs

Energy Elficiem Canning

High Ellicioncy Wald Unit

Hyperfiltration: Food

Hyperfiltration: Textiles

Improved Diesel Engines

Irrigation Systems

Methanol Recovery Process

Nitrogen-Methanol Carburization

PET Bottle Separator

Plating Waste Concentrator

Recuperators (GTE)

Reverse Brayton Cycle Solvent Recovery

Slot Forge Furnace/Rncuperator

Solvent Recovery Irom Etrluent Streams

Waste Energy Rocovery

DOE Investmemt

Dollars Saved

Not Available
(\$1,300,000)

Not Available

Not Available

$\mid \$ 1,400,000)$

$1 \$ 11,850,000)$ (5458,000)

Not Available

Mot Available

$\mid \$ 372,000\}$

Not Available

(\$035,000)

Not Available

$(\$ 1,500,000)$

Not Available

(\$370,000)

$(\$ 1,500,000)$

(\$450,000)

$\mid \$ 2,600,000)$

(\$5,415,000)

$(\$ 2,400,000)$

1\$416,000)

(\$15,000)
$\$ 10.397 .670$

$\$ 24, B 36,661$

$\$ 123,019,115$

$\$ 34,196$

$\$ 118,676,697$

$\$ 171,914,109$

$\$ 68.567,974$

$\$ 310,488,817$

$\$ 7,141,531$

$\$ 155,756,500$

$\$ 11,351,605$

$\$ 1,212,516$

$\$ 200,037,504$

$\$ 288,511,032$

$\$ 288,112$

$\$ 1,391,175$

$\begin{array}{r}\$ 0 \\ \hline\end{array}$

$\$ 1,200,524$

$\$ 60,290,333$

$\$ 2,110,593$

$\$ 30.091,201$

$\$ 0$

$\$ 35,807,912$
$\$ 26,130,601$

$\$ 120,076,697$

$\$ 183,764,109$

$\$ 69,025,974$

-

$\$ 156,128,500$

$\$ 1,847,516$

$\$ 290,011,032$

$\$ 1,761,175$

$\$ 1,500,000$

$\$ 4.650 .524$

$\$ 62,890,333$

$\$ 7.525 .593$

$\$ 32,401,201$

$\$ 446,000$

$\$ 35,822,812$ 
- Units Decommissioned. The number of units decommissioned in a particular year.

- Total Units Decommissioned to Date. The total number of units of the technology decommissioned as of the date of the column.

- Total Units Operating to Date. The cumulative number of units installed to date minus the cumulative number of units decommissioned to date (as of the date of the column in which the number appears).

- Units Transferred to Table 4.2. The total number of units moved to the mature technologies table (equals the number of units installed ten years before for the particular column).

- Total Units Transferred to Table 4.2 to Date. The cumulative number of units transferred to the mature technologies table as of the date of the column.

- Total Number of Units Tracked in Table 4.1. The total number of units tracked (cumulative up to the date of the column) in the commercially successful technologies table.

The next portion of the technology-specific summary tables contains detailed information concerning the energy savings of the technology on a yearly basis. The contents of this portion of the summary tables are described below:

- Savings Due to Units Installed in Current Year. The energy savings attributable to those units installed in the year given by the column heading only. These numbers are not cumulative; hence, if no units were installed in 1987 (for instance) but some were installed in 1986, energy savings would appear in the 1986 column but not in the 1987 column.

- Energy Savings from Units Decommissioned in Current Year. Figures for the amount of energy savings attributable to any units that may have been decommissioned in the year indicated by the column heading.

- Current Year Energy Savings from All Operating Units. The energy savings from all units installed to date (the date of the column) minus the energy savings of any units that were decommissioned.

- Cumulative Energy Savings of All Operating Units Across Years Up to Current Year. The total energy savings of all operating units cumulative across all the years up to the year given by the column heading (i.e., it contains the running total of the row above it).

- Current Year Energy Savings from All Operating Units Transferred to Table 4.2. The energy savings for the year of the column heading only that are moved to the mature technologies table. They are the savings of those units still operating that were installed ten years previously. 


\section{- Cumulative Energy Savings of All Operating Units Across Years Up to Current Year Transferred to}

Table 4.2. The running total of the row above.

- Current Year Energy Savings from All Operating Units. The energy savings reported in this row appear in the commercially successful technologies table as the "Estimated Energy Savings" and are those from the row entitled "Current Year Energy Savings from All Operating Units" minus "Current Year Energy Savings from All Operating Units Transferred to Table 4.2."

- Cumulative Energy Savings of Operating Units Across Years Up to Current Year. Contains the energy savings reported in the commercially successful technologies table in the column "Cumulative savings" and is the running total of the row above.

- Current Year Energy Savings Rate (All Units). The numbers in this row reflect the energy savings rate (for the current year) of all operating units that would have resulted had those units installed in the year given by the column heading been operational for a complete year rather than a fraction thereof.

- Current Year Energy Savings Rate (2 Units). The energy savings rate of those units transferred to the mature technologies table.

- Net Current Year Energy Savings Rate (1 Units). The energy savings rate (for the current year) obtained by taking the "Current Year Energy Savings Rate (All Units)" minus the "Current Year Energy Savings Rate (Table 4.2 Units)."

Below the energy savings portion of the technology-specific summary tables are two additional subtables. The first of these (entitled "Summary Information for Table 1") contains data extracted from the units and energy savings subtables for the year appearing at the top of the subtable (in red), which also appear in the commercially successful technologies and mature technologies tables in the row dealing with that technology. The second table indicates what type of fuel is saved through the use of the technology.

Finally, below the fuel table appears a table with dollar values for DOE investment in the technology, as well as dollar values associated with the energy savings according to fuel type saved. These dollar values are based upon the year indicated by the user, as set by the "Current Year" (see below in Section 5.0 on how to set the current year), and are shown on a yearly basis.

A sample of one such technology-specific table appears in Table 4.5 (in this case, for the biomass grain dryer technology). Due to the size of these tables, only a few sample years are shown. The table extends from 1977 through 1993. 
Table 4.5. Sample Technology-Specific Summary Table

\begin{tabular}{|c|c|}
\hline $\begin{array}{c}1993 \\
\text { SUMMARY INFORMATION FOR TABLE } 1\end{array}$ & \\
\hline Tofal units linstalled to daie & 31 \\
\hline Tolsi cinits decominissloned lo date & 0 \\
\hline Tolinl unilts transferred to Table 2 lo dale & 20 \\
\hline Tolal unils iracked af lindicated tine & 11 \\
\hline Current Year Energy Savings tianslerled to Table 2 & $1.54 E+10$ \\
\hline Cumulative Energy Savings liansferied to Table 2 & $5.95 \mathrm{E}+10$ \\
\hline Table 1 Current Yeai Energy Savings & $8.03 E+10$ \\
\hline Fable 1 Current Year Energy Savings Rate & $8.03 E+10$ \\
\hline Table i cumulalive Energy Savings & $8.39 E+11$ \\
\hline
\end{tabular}

\begin{tabular}{|c|c|c|}
\hline & \multicolumn{2}{|c|}{ FUEL INFORLIATION } \\
\hline & TYPE OF FUEL SAVED & PERCENT \\
\hline & $\begin{array}{l}\text { Coal (C) } \\
\text { Feedstock Chenucals (Ch) }\end{array}$ & \\
\hline & Eleriflicily (E) & $80 \%$ \\
\hline & Fuel Oil (F) & \\
\hline & Gasolirie (G) & \\
\hline & I latural ras (IIS) & \\
\hline- & Other (O) & \\
\hline & Frupane (I) & $20 \%$ \\
\hline & Rr-Inuely Gas (RRC) & \\
\hline
\end{tabular}

\begin{tabular}{|c|c|c|c|c|c|c|}
\hline Activily'rear & 1977 & 1978 & 1979 & 1980 & 1981 & 1982 \\
\hline TOE liveslinent & & & (\$105,000) & & & \\
\hline Dollar Value uf Energy Savings by Fuel Type & & & & & & \\
\hline Coal (C) & $\$ 0$ & \$0 & $\$ 0$ & \$1) & \$o & $\$ 0$ \\
\hline Feedslock Cliemicals (Ch) & $\$ 0$ & $\$ 0$ & $\$ 0$ & \$o & $\$ 0$ & \$0 \\
\hline Eleclicicity (E) & $\$ 0$ & $\$ 0$ & $\$ 0$ & $\$ 78,494$ & $\$ 240,288$ & $\$ 408,652$ \\
\hline Fuel Oil (V) & $\$ 0$ & $\$ 0$ & $\$ 0$ & $\$ 1$ & $\$ 0$ & $\$ 0$ \\
\hline Gasoline (G) & $\$ 0$ & $\$ 0$ & $\$ 0$ & $\$ 0$ & 10 & so \\
\hline Maltw al Gas (N/G) & $\$ 0$ & \$n & $\$ 0$ & $\$ 0$ & $\$ 0$ & so \\
\hline Other (O) & \$o & \$0 & \$0 & $\$ 0$ & $\$ 0$ & $\$ 0$ \\
\hline Propane $(P)$ & $\$ 0$ & $\$ 0$ & \$o & $\$ 7.892$ & $\$ 24,161$ & $\$ 41,090$ \\
\hline Refinery Gas (FG) & \$n & $\$ 0$ & $\$ 0$ & $\$ 0$ & $\$ 0$ & so \\
\hline Gross Dollial Savings & $\$ 0$ & \$o & $\$ 0$ & $\$ 86,386$ & $\$ 264.448$ & $\$ 4.49 .742$ \\
\hline Ilet Dullar Value of Energy Savings & $\$ 0$ & \$0 & (\$105.000) & $\$ 86,386$ & $\$ 264,448$ & $\$ 449,742$ \\
\hline Curnufalive linvestmenl & \$0 & $\$ 0$ & $(\$ 105,000)$ & $(\$ 105,000)$ & $(\$ 105,000)$ & $(\$ 105,000)$ \\
\hline Cumnhillive Gross & $\$ 0$ & $\$ 0$ & 90 & $\$ 86.386$ & $\$ 350,835$ & $\$ 800,577$ \\
\hline Curmulalive Het & \$o & \$0 & (\$105.000) & $(\$ 18,614)$ & $\$ 245,635$ & $\$ 695.577$ \\
\hline
\end{tabular}

\begin{tabular}{|c|c|}
\hline ECONOMIC SUMMIARY INFORMIATION & 1993 \\
\hline Sumulalive Investinent & $(\$ 105.000)$ \\
\hline Eumulalive Savings & $\$ 10.397 .676$ \\
\hline
\end{tabular}


Table 4.5. (contd)

\title{
Technology: Biomass Grain Dryer
}

\author{
Press tlis button for detail on specilic unit \\ installed (where, production rate, etc.)
}

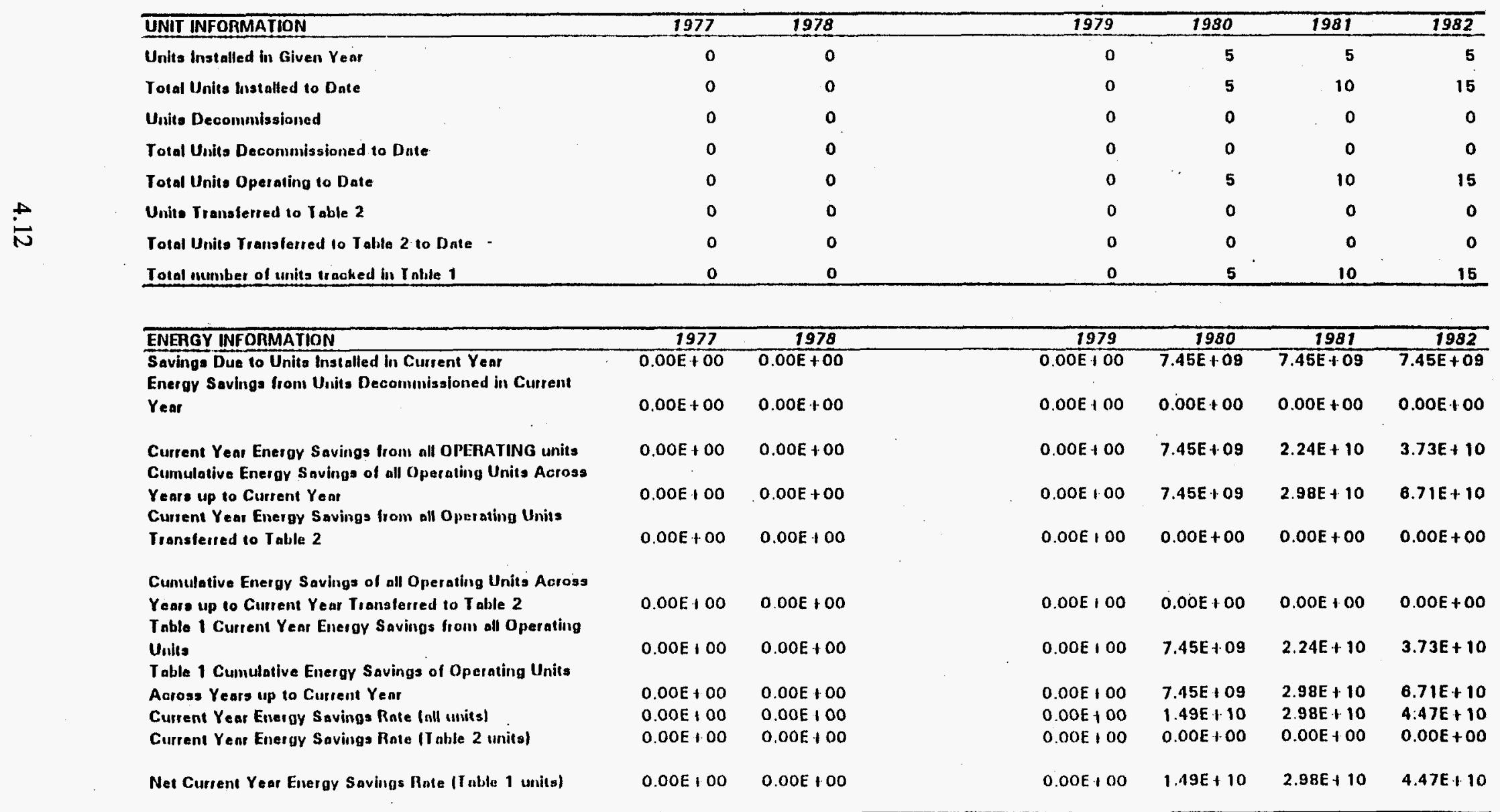




\subsection{Energy Savings Calculation Methodologies}

The energy savings calculation methodologies provide information on the assumptions and typical parameters employed in the energy savings calculations (for those technologies with energy savings). In addition, sample calculations are provided. It is important to note that the sample calculations are intended to provide an outline of the energy savings calculation only, to provide the user with a feel for how these numbers were derived. Because many of the parameters used in the calculations differ from one unit to the next, it is impossible to recreate the energy savings figures appearing in the commercially successful technologies or the mature technologies tables from these methodologies alone. To do this, one would examine the technology-specific summary file pertaining to the technology of interest. With this file (containing the actual numbers appearing in both the commercially successful technologies and the mature technologies tables), the exact development of the technology can be followed. As many of the numbers appearing in the technology-specific summary files are generated by formulas (which are themselves not visible unless one turns on the formula display) that have no label, and the calculation methodologies file is useful in identifying some of these parameters. Methodologies for all the technologies found in the commercially successful technologies table appear in the energy savings calculation methodologies file.

\subsection{Technologies of the TBRS}

Each technology appearing in the commercially successful technologies table, those technologies in the mature technologies table that also appear in the commercially successful technologies table, and a growing number of technologies appearing in the emerging technologies table (particularly those closest to commercialization) have an associated background file. This file contains supplemental information on these technologies that provide the user of the TBRS with an explanation of the technology and its associated benefits. Specific topics contained in these files are highlighted below:

- General. This section provides overview information on the technology (what it is, what it achieves) and the DOE's role in its development and/or commercialization.

- History. More detailed background on the technology and the role of the DOE in its development is provided in this section. Information regarding the markets the technology competes in, difficulties it may have encountered in its commercialization, and other topics are discussed.

- Technology Description. This section contains a description of the technology itself, as well as an explanation of the origins of the energy savings attributable to the technology.

- Non-Energy Benefits. Many technologies included in the TBRS have benefits as well as energy savings (and some have only non-energy benefits). These benefits are described below. If no benefit exits for a technology in a particular category, the text "No Benefit Identified" appears.

- Environmental Benefit. Any benefit to the environment accruing through the use of this technology is documented in this section. Note that any technology with an energy savings benefit has a 
secondary environmental benefit resulting from avoided emissions productions as a result of reduced energy consumption reduction.

- Productivity Improvements. The effect of the technology, if any, on improved productivity (e.g., faster drying, curing, production) is listed in this section.

- Labor Improvements. Any effect of the technology on direct job creation or deletion is catalogued in this section. Secondary job creation (such as determined through an economic input-output model) figures are not presented here.

- International Competitiveness. Another area of interest is the technology's possible impact on the international competitiveness of U.S. industry. An identified impact the technology has had in this respect is discussed here. Units of the technology exported to foreign countries are also mentioned in this section.

In addition to these text items, graphics (either photos or diagrams) of certain technologies are available when the TBRS user is in the qualitative background files. For a description of how to access these graphics, refer to Section 5.0.

The contents of the background files are found in the appendix to this report. Although many additional technologies appear throughout the system, extensive background files, such as those found in the appendix (as of the date of this publication), exist only for those technologies that appear in the commercially successful technologies table.

\subsection{Miscellaneous Supporting Tables}

In addition to the tables and files described in the sections above, the TBRS contains a number of other resources. The first of these is the cross-references or "aliases" table. This table serves as a crossreference and index of technologies contained in the TBRS. All technologies contained in the TBRS are listed here, along with the table in which they appear. Additionally, any other names by which the technology is referenced in other DOE or industry literature appear here (to the extent that PNL is aware of such other names).

Another table, the inactive technologies table contains a listing of technologies that will never be tracked in the TBRS, as they will never be commercialized for a variety of reasons. Typical explanations would be that the technology was never fully developed or was surpassed by a superior technology, etc. 


\subsection{Operation of the TBRS}

This section of the report details the operation of the TBRS. Section 5.1 describes the computational requirements to run the TBRS as well as to install the system. Section 5.2 describes using the TBRS.

\subsection{Getting Started}

Before using the TBRS, the user must install the system on his or her personal computer system. Basic computational requirements as well as the installation procedure are described in the next two sections.

\subsubsection{Hardware and Software Requirements}

To run the TBRS, the following hardware and software are required:

- IBM or compatible $386 \mathrm{SX}$ (or later) processor

- 3 MB RAM

- $20 \mathrm{MB}$ free hard-disk space

- VGA color monitor

- Microsoft Excel ${ }^{\mathrm{TM}}$ 5.0.

It is strongly recommended that the system also have the following:

- $486 \mathrm{DXII} 66 \mathrm{MHz}$ (or better) processor

- 16 MB RAM

- Super VGA color monitor.

\subsubsection{Installing the TBRS}

To install the TBRS, simply copy the files (found on the disk provided) into an empty directory on your hard drive. 


\subsubsection{Creating an Icon for Activating the TBRS}

Access to the TBRS is simplified by first creating an icon on your Windows ${ }^{\mathrm{TM}}$ Program Manager screen in a program group of your choosing. To do this, follow the instructions provided in your Windows User's Guide. After listing the path and name of the Excel ${ }^{\mathrm{TM}}$ executable program, provide the path and name of the file TRACK93.XILW (this will be copied to an empty directory). As the working directory, provide the name of the directory into which you copied the files provided on disk.

\subsection{Using the TBRS}

This section describes how to operate the TBRS. Navigatation through the system and instructions on changing various system-wide settings are provided.

\subsubsection{Navigation Through the TBRS}

The information contained in the TBRS can be accessed in a variety of ways the following sections describe the recommended method for doing so.

\subsubsection{Starting the TBRS}

To start the TBRS, double click on the icon you created for the TBRS. The cover screen will appear and the workspace will be customized for the TBRS. After a short delay the contents and settings screen will appear.

\subsubsection{The Contents and Settings Screen}

The contents and settings screen is the central parameter setting and branching screen. At this location, the user can set a variety of parameters employed throughout the system, such as the current date (described in Section 4.0) and the discount rate (the rate employed by the system for calculating the present value of energy savings figures).

Below the background section appears the Features and Settings box. By pressing the button entitled New Year, the user can set a date that becomes the driver for the information displayed in all the singleyear and cross technology files, as well as the base year for the dollars shown in the energy prices table (e.g., 1991 dollars, etc.). A year between 1973 and 1993 can be entered (at the time of this printing, 1993 was the latest year of data in the system).

Similarly, by pressing the New Rate button, the user can set the discount rate employed in the present value calculations that result in the dollar values appearing in the energy prices table. 
The next three buttons take the user to the commercially successful technologies, the mature technologies, and the emerging technologies tables, respectively. Pressing the Calculations button takes the user to the calculation methodologies sheet.

The last button on this screen exits the system. Pressing this button is the only means by which the user should exit the system. Exiting in any other fashion will result in Excel ${ }^{\mathrm{TM}}$ not functioning properly when used with other applications.

\subsubsection{The TBRS Button Bar}

The primary means of navigation throughout the TBRS is the TBRS button bar that appears on the right side of the screen after the system has loaded. The buttons appearing on this button bar and their function are provided in Figure 5.2. In addition to being described briefly in the following paragraphs, the function of each of these buttons is discussed in the relevant sections below describing work-sheet navigation.

To print various items within the TBRS, press the Print button. Doing so offers the user four options: 1) printing the currently open cross-years summary table (if one of these tables is open), 2) printing all of the cross-years summary tables, 3) printing the currently open technology qualitative background sheet, or 4) printing all of the qualitative background sheets.

To use the Qualitative Support Sheet button, one must first be in either the commercially successful technologies, the mature technologies, or the emerging technologies tables, with the name of a particular

\begin{tabular}{|c|c|}
\hline $\begin{array}{r}\text { PRINT } \\
\text { SUPPORT SHEET } \\
\text { PICTURE } \\
\text { METHODOLOGIES } \\
\text { TECHNOLOGY SPECIFIC SHEET } \\
\text { SET CURRENT YEAR } \\
\text { CONTENTS AND SETTINGS } \\
\text { COMMERCIALLY SUCCESSFUL } \\
\text { MATURE TECHNOLOGIES } \\
\text { EMERGING TECHNOLOGIES } \\
\text { CROSS REFERENCES } \\
\text { SET DISCOUNT RATE } \\
\text { DOLLAR SAVINGS SHEET } \\
\text { SAVINGS CHART }\end{array}$ & 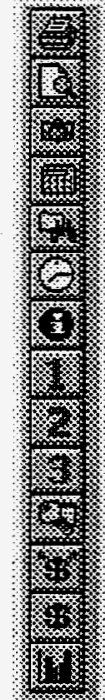 \\
\hline
\end{tabular}

Figure 5.1. The Buttons and Their Associated Functions on the Technology Tracking Toolbar 
technology selected. The Qualitative Support Sheet button then opens the qualitative support sheet associated with the selected technology. If such a sheet does not exist for the selected technology, a message to this effect appears.

The Picture button is used to open a photo or diagram of a particular technology. The Picture button can only be used while the user is in a qualitative support sheet. If the user is not in such a sheet, a message prompting the user to shift to a qualitative support sheet is displayed.

The Methodologies button duplicates the function of the Calculations button on the contents and settings screen in that it transfers the user to the calculations methodology support sheet.

The technology-specific sheet shifts the user to one of the technology-specific tables, based on which technology has been selected in either the commercially successful technologies, the mature technologies, or the emerging technologies tables. To use this button, the user must be in one of these tables.

The Set Current Year button duplicates the New Year button on the contents and settings sheet. Pressing this button allows the user to change the current year used in the summary tables.

The Contents and Settings button takes the user to the contents and settings screen.

The next three buttons take the user to the commercially successful technologies, the mature technologies, or the emerging technologies tables, respectively.

The Cross-Reference button switches the operator to the cross-referencing (or aliases) sheet.

Pressing the Set Discount Rate button prompts the user to enter a discount rate for use in calculating dollar values associated with the energy savings of the technologies. The Dollar Savings Sheet button accesses the savings summary sheet.

Finally, pressing the Savings Chart button creates a chart of the investment by DOE in dollars and the dollar savings of the technology (both are presented year by year), as well as the cumulative number of units sold. This button only operates if the user is in a quantitative technology-specific table.

\subsubsection{Changing the Current Date and Discount Rate}

The current date and the discount rate can be changed in two ways. First, these operations may be performed by pressing the New Year or the New Rate buttons, respectively, on the contents and settings sheet. Alternately, the user can use the Set Current Year or the Set Discount Rate buttons from any point within the TBRS. Any discount rate can be used (although the numbers should be positive), but the date entered must be between 1977 and 1993 (inclusive). 


\subsubsection{Accessing the Single-Year Summary Tables}

To access either the commercially successful technologies, mature technologies, or the emerging technologies tables, the user can either press the Table 1, Table 2, or Table 3 buttons (respectively) on the contents and settings sheet, or press the buttons with the 1,2 , or 3 on the TBRS toolbar. This action will switch the user to these files from anywhere within the system.

\subsubsection{Accessing the Technology-Specific Files}

To access the technology-specific files, first select one of the technologies appearing in either the commercially successful or mature technologies tables. Then press the Technology Specific Sheet button. If a file exists for the technology, the TBRS will switch to the appropriate file.

\subsubsection{Displaying Contact and End-User Information}

While in a technology-specific file, detailed information can be accessed on specific industry contacts for the technology, as well as energy consumption and sales information at the level of distributors of the technology or actual endusers of the technology (depending upon who is contacted by PNL to determine this information). To access this information, simply press the button on the sheet that states, "Press here display industry contacts, etc." To hide this information, press the button titled, "Press here to hide this information."

\subsubsection{Displaying the Energy Savings and Investment Graph}

While within a technology-specific file, the user can display a chart of DOE's investment in the technology and the dollar value of the energy savings of the technology, both on a year by year basis. The number of units of the technology, on a cumulative basis, is also shown on the same graph. A table in the upper right corner of the graph provides the total cumulative DOE investment and total cumulative dollar value of energy savings, both as of the year set as the current year. The ratio of cumulative savings to cumulative investment is also provided.

While in this chart, the TBRS button bar is replaced with the buttons for changing the current date, discount rate, and a chart button. Pressing the Chart button while in the chart exits the chart.

\subsubsection{Accessing the Calculation Methodology File}

To access the file containing the calculation methodologies, press the Calculation Methodologies button on the TBRS toolbar, or the Calculations button on the contents and settings sheet. 


\subsubsection{Qualitative Background Files}

To access the qualitative background file for a particular technology, highlight the technology of interest in either of the commercialized, mature, or emerging technologies tables. Then press the Qualitative Support Sheet button. The desired qualitative sheet will appear, if it is available.

While within the qualitative background file, press the Picture button to display a photo or diagram of the technology. If a photo or diagram is not available, a message to that effect is displayed. While viewing the photo diagram, the TBRS toolbar disappears, except for the Picture button. Pressing the Picture button while within a picture exits that file and returns the user to the qualitative sheet.

\subsubsection{The Cross-Reference File}

The file containing a comprehensive list of all technologies included in the TBRS, the cross-reference (or aliases) file, also contains other names by which the technologies are referred, where they appear in the system, and other information. This file is accessed by pressing the Cross-References button on the TBRS toolbar.

\subsubsection{Printing}

Using the Print button on the TBRS toolbar, the system user may automatically print the single-year summary tables or the qualitative background files. Pressing the Print button displays the Print Dialog box. This box offers the user four print options: to print the currently active single-year summary table (only usable while one such table is active), all of the single-year summary tables, the currently active qualitative background file (only when a qualitative background file is active), or all the qualitative background files. The latter option also prints the calculation methodology file. 


\subsection{The Future of the TBRS}

The TBRS will be updated annually. New technologies will be added to the system as the OIT commercialization program continues to evolve. Future releases of this program are expected to contain photos and supporting materials for each technology. As computational resources continue to grow and as Excel $^{\mathrm{TM}}$ software is upgraded, the TBRS will be expanded to accommodate these changes. PNL expects the TBRS to be made available on CD-ROM in the near future. 


\section{Appendix}

Technology Background Files and Supporting Information 


\section{Biomass Grain Dryer}

\section{General}

High-temperature grain dryers are used to reduce the moisture content of grain, typically by $5 \%$ to $10 \%$, prior to grain storage. The U.S. Department of Energy (DOE) funded the development of a furnace fired with crop residues for use in grain drying. Sukup Manufacturing Company (Sukup) is the sole licensor of this technology.

\section{History}

In 1978, DOE funded Iowa State University to develop a biomass-fueled grain dryer to reduce the moisture content of grains prior to their storage and transport.

Sukup's biomass grain dryer has two traditional market applications: drying in the corn seed industry and on individual farms. To date, Sukup has sold 25 units for these market applications. No units have been sold since 1985 for grain-drying applications; all 25 units had been sold between 1980 and 1985 when energy prices were high.

In 1991 Sukup identified a new market application for the biomass dryer. The units are now being used by furniture manufacturers for the dual purposes of scrap disposal and space heating. This application is better suited to the technology because it has a 12-month operating schedule that reduces the payback period. The traditional application of grain drying has a 30- to 60-day operating schedule; thus, payback occurs over several seasons.

As of 1991, Sukup had sold approximately 27 units in the United States. Two units were installed in a furniture factory during the 1991 heating season. Two units were expected to be installed in wood-scrap burning applications by the end of 1991 .

\section{Technology Description}

The prototype developed at Iowa State University was rated at $1 \mathrm{MMBtu} / \mathrm{h}$, had a horizontal combustion chamber, and circulated exhaust gases directly through the grain bin. Sukup's model is a fourthgeneration version of the original work performed at lowa State University. The unit produced by Sukup is rated at 3.5 MMBtu/h and is automatically fed with corn cobs, wood chips, or other biomass fuels. It uses a heat exchanger for preheating combustion air and has a vertical combustion chamber. 


\section{Benefits}

\section{Energy Benefit}

The energy benefit of this technology is shown in Table 4.2 on page 4.4 .

\section{Environmental Benefit}

The new application has two advantages for system users: 1) the units enable the furniture manufacturer to avoid landfill charges for scrap disposal, and 2) the units reduce the firm's space heating bill during the heating season. The two units provide a $7 \mathrm{MMBtu} / \mathrm{h}$ capacity that exceeds the heating requirements of the $225,000 \mathrm{ft}^{2}$ high-bay plant.

\section{Quality Improvements/Technical Advantages}

None identified.

\section{Productivity Improvements}

None identified.

\section{Labor Improvements}

None identified.

\section{International Competitiveness}

None identified.

\section{Current Status}

The two wood-burning units that were expected by the end of 1991 have been installed; however, neither unit will contribute to the energy savings calculation. One of the units was installed solely for scrap burning, and the purchaser of the second unit does not wish to be contacted (according to Sukup). In June of 1992, Pacific Northwest Laboratory (PNL) requested and received information on installation locations in the United States. Sukup's response listed 29 grain-drying installations, which included four more installations than PNL's records showed. The existence of these four units was verified in the annual contact, and these four units will be added to the table; a full year's energy savings will be associated with them for 1992. To recap, Sukup has sold 29 units for grain-drying applications, and two units for scrap-burning/space-heating applications. 
After repeated attempts, Sukup could not be contacted in 1993. For this reason, no new units will be added to the table for this technology. The same quantity of energy savings that occurred in 1992 will be assumed to have been achieved in 1993 . 


\section{Catalytic Reactor}

\section{General}

Chemical Research and Licensing Corporation (CR\&L) developed a distillation unit for producing methyl-tertiary-butyl-ether (MTBE), a gasoline additive that uses the heat of reaction of the feedstock chemicals to drive the distillation process, avoiding separate energy input. The catalytic distillation technology has also been used to successfully produce tertiary-amyl-methyl-ether (TAME), which is also a gasoline additive.

\section{History}

This technology was first demonstrated commercially in 1981 with funding from DOE. By 1991, seven MTBE units were operating in the United States and twelve units were operating world-wide. The seven domestic units were located at Charter International Oil Refinery, Houston, Texas; Amoco Oil Refinery, Whiting, Indiana, and Yorktown, Virginia; Fina, Big Spring, Texas; Exxon Chemical Company, Baton Rouge, Louisiana; Mobil Oil Co., Beaumont, Texas; and Chevron's El Segundo, California.

\section{Technology Description}

MTBE or TAME can be made by reacting methanol with isobutylene or isoamylene over an acid resin catalyst. These iso-olefins are present as co-products from refinery Fluid Catalytic Cracking (FCC) units and ethylene plants. Under normal conditions, the reaction cannot proceed to completion because of a reversible reaction that approaches equilibrium. The practical conversion limit for isobutylene is about $97 \%$, while isoamylene is limited to around $70 \%$ conversion in a conventional fixed-bed reactor. Catalytic distillation relaxes this limit by removing the reaction products while simultaneously catalyzing the reaction. This approach minimizes the effect of the reverse reaction and allows the forward reaction to proceed to greater levels of conversion. Isobutylene conversion greater than $99 \%$ and isoamylene conversion in excess of $95 \%$ can be achieved by applying this technique. The catalytic distillation process is not like a fixed-bed reactor. Simply scaling up on residence time does not produce the desired results. Other things such as catalyst height, pressure drop, reflux rate, and the change in concentration because of distillation have to be considered. 


\section{Benefits}

\section{Energy Benefit}

The energy benefit of this technology is shown in Table 4.2 on page 4.4 .

\section{Environmental Benefit}

The Clean Air Act Amendment of 1990 has legislated the use of oxygenates in gasoline in areas where ozone or carbon monoxide cause significant pollution problems. U.S. refiners have been evaluating various options to modify their plants for compliance with the reformulated gasoline. Most refiners have expressed a preference for ethers rather than alcohols to satisfy the oxygenate requirements (MTBE and TAME are both ethers). TAME production removes some of the most atmospherically reactive hydrocarbons (isoamylenes) form the gasoline pool. In simple terms, the catalytic distillation process produces more MTBE or TAME than conventional processes using identical amounts of raw feedstock.

\section{Quality Improvements/Technical Advantages}

None identified.

\section{Productivity Improvements}

None identified.

\section{Employment}

None identified.

\section{International Competitiveness}

CR\&L this year reported that 13 units were in operation overseas.

\section{Current Status}

The future for this technology appears to be especially bright, because CDTECH (a new partnership between CR\&L and ABB Lummus Crest, Inc.) now has over 80 MTBE and TAME units "awarded." Today, the driving force for success was unforeseen in 1981. In the 1990s, environmental quality has become an overriding concern. The Clean Air Act Amendment of 1990 has legislated the use of oxygenates in gasoline in areas where ozone or carbon monoxide cause significant pollution problems. U.S. refiners have been evaluating various options to modify their plants for compliance with the reformulated 
gasoline. Most refiners have expressed a preference for ethers rather than alcohols to satisfy the oxygenate requirements. All of these events have contributed to a tremendous future demand for oxygenates. This demand will far surpass the current capacity for MTBE, which is limited by the supply of isobutylene. TAME, which is produced from isoamylenes products of the FCC and by-products of steam cracker operations will make a significant contribution to the predicted oxygenate requirement.

The first TAME-producing plant and three new MTBE plants began U.S. operation in September 1992. CR\&L reported 32 units in operation world-wide, 19 of which are located in the United States. Because our records indicate that nine units were operating as of September 1992, 23 should be added for the fiscal year (FY) 1993 reporting period (10 more in the United States and 13 overseas). No details were given as to exactly where or when the 10 new units were installed. These new units produce an average of 2,000 barrels per day.

The main barrier that the technology has encountered is a lack of capital in the oil industry. CR\&L indicated that the oil industry is spending money to modify processes to comply with the Clean Air Act, and these activities compete with the technology for industry funds. The Clean Air Act has helped this technology because certain properties of the process also help the plants comply with the Act. 


\section{Cement Particle-Size Classifier}

\section{General}

The O-SEPA Air Separator (O-SEPA) unit reduces power costs through higher milling efficiency by separating out particles that have reached the desired size range. The unit also reduces new capital expenditures by increasing capacity up to $50 \%$ for a given mill size. The separator is used to process cement, lime, coal, phosphate, bauxite, clay, sand, etc. Energy savings average about $15 \%$ to $20 \%$ of the electrical energy required to power the grinding mill motor. The quality of the finished material is improved through a narrower particle-size distribution.

\section{History}

The DOE contracted with Fuller Co. to demonstrate the separator in a U.S. cement mill. Since that time, there have been approximately 52 U.S. installations of the O-SEPA cement classifier.

\section{Technology Description}

The O-SEPA unit falls into the category of classifiers known as side-draft classifiers. This type of classifier creates a horizontal air stream that acts on the downward-falling cement particles. All or most of the air in the classifier is blown (by an external fan unit) sideways through a volute that provides an even, radial distribution of air. Particles carried by the air are classified in a narrow separation zone. Coarse particles drop through an annular space between the rotor and the volute into one or more collection cones. Fine particles are swept inside the rotor and pass to external collectors through a top discharge vent.

\section{Benefits}

\section{Energy Benefit}

The energy benefit of this technology is shown in Table 4.2 on page 4.4 .

\section{Environmental Benefits}

The O-SEPA Air Separator has the benefits of reducing power consumption in grinding operations and typically realizes a $20 \%$ reduction in power. This results in reduced emissions of $\mathrm{SO}_{x}, \mathrm{NO}_{x}$, and $\mathrm{CO}_{2}$. 


\section{Quality Improvements/Technical Advantages}

The classifier produces a better particle-size distribution in the cement. The spermine particles and the very coarse fractions are eliminated because the cement is primarily between 5 to 35 microns. This results in an improved development in compressive strengths, often allowing the cement fineness to be reduced for the same strength. Consequently, the power consumption in grinding is less, or alternately a higher production rate is attained.

\section{Productivity Improvements}

Typically, a $25 \%$ to $30 \%$ improvement in production can be noted.

\section{Employment}

The industry contact was not aware of any reduction in labor force resulting from the use of the classifier. However, its has resulted in superior operation, requiring less attention and maintaining high quality.

\section{International Competitiveness}

This year, 177 units from overseas sales have been added to the benefits database. Energy savings from these units is assumed to have begun in 1993.

\section{Current Status}

There are 215 units in operation world-wide. Fourteen units have been sold in 1992 and 1993 . Three units were sold in the United States, and the remainder of the units were sold overseas in India, Latin America, and the Far East. The industry contact was not aware of any units that have been decommissioned. 


\section{Chemical Separation by Fluid Extraction}

\section{General}

CS Systems, Inc., developed a new chemical separation process that uses fluid extraction technology. This system recovers organic material and effluents that cannot be recovered using other conventional technology.

\section{History}

DOE contracted with CS Systems to develop a chemical separation system that uses fluid extraction. The system would recover organics and effluents and be more energy efficient than previous systems.

\section{Technology Description}

Solvent extraction technology uses a liquefied gas solvent, such as propane or carbon dioxide, to extract organics from solids, sludges, and aqueous streams. Following extraction and separation (the extract phase from the treated material phase), solvent is recovered from the extraction system. Extraction organics are recovered from the system for recycle, reuse, or disposal.

The primary energy benefit of this technology stems from the recovery of oil in waste streams at refineries. The fluid extraction technology represents a way to extract oil from waste streams that would normally be discarded. This oil can then be reprocessed as fuel for boilers or can be put back into the normal process. This technology can also be used to extract chemicals for use in feedstock for other processes. The new chemical separation design technology can replace thermal treatment processes for remediation projects, resulting in a significant energy savings.

\section{Benefits}

\section{Energy Benefit}

The energy benefit of this technology is shown in Table 4.2 on page 4.4. 


\section{Environmental}

Solvent extraction technology can be used to meet current regulations for treatment of most organic contaminated wastes including soils, sludges, waste waters, clays, silts, and sediments contaminated with volatile organic compounds (VOCs) including benzine, toluene, xylenes, trichloroethylene, tetrachloroethylene, poly-nuclear aromatics, naphthalene, phenanthrene, chrysene, polychlorinated biphenyls (PCBs), polychlorinated phenyls, dioxins, furans, oxgenates, alcohols, and acids. Other environmental benefits are the recovery of organics that are normally lost in effluents from a process and cannot be recovered by other conventional technology. Following treatment and resource recovery, the organics are recycled and the treated residues may be used as feedstock for other process operations but will no longer be hazardous due to organic content.

\section{Quality}

The following quality improvements can be expected from implementation of the technology for treatment of ongoing wastes or remediation of existing wastes.

- The treated residues will meet disposal standards for organic contamination.

- The extracted organics can be recycled for reuse or readily disposed of.

- There are no atmospheric emissions for the process.

- The technology is commercially proven and demonstrated over a period of time.

\section{Productivity}

In resource recovery applications, the technology can be used to recover recycled organics that are normally lost as effluents in the process and cannot be recovered by conventional technology, such as distillation by thermal recovery. The recovery of valuable product normally lost in process effluents can be a significant improvement to productivity. Because of their organic contents, the effluents frequently need to be disposed of as a hazardous waste, via incineration or landfill. Following treatment and resource recovery, the organics are recycled and the treated residues may be used as feedstock for other process operations. The results are no longer hazardous after the organics have been removed.

\section{Labor}

No labor impact of the technology has been identified. 


\section{International Competitiveness}

None identified.

\section{Current Status}

Only two units have been sold since 1990 . Several projects are in the design or development stages. The energy savings from these units have been added to Table 1 (under Chemical Separation by Fluid Extraction). 


\section{Cogeneration - Coal-Fired Steam Turbine}

\section{General}

A cogeneration system based on a coal-fired boiler that produces high back-pressure has been developed to meet industrial steam and electricity requirements. Such a system could be installed in any industrial plant that requires both process steam and electricity.

\section{History}

The original unit demonstrated with DOE funding was installed at the Riegel Textile Plant in Ware Shoals, South Carolina. This plant closed in 1984, resumed operations under different ownership in 1986, and closed again in 1988.

A coal fired, low-pressure system went into operation in November 1984 at Burlington Industries, Raeford, North Carolina; Alternate Energy Corporation was the promoter of this installation. This unit operated a total of 100 to 150 hours in 1989 because of a boiler problem, and the unit operated steadily during 1990.

Cogentrix of North Carolina is currently the strongest promoter of this technology. Certain industry contacts have cited the Clean Air Act and its amendments as a barrier to the adoption of this technology in some cases.

\section{Technology Description}

This technology employs a specially designed system in which high-pressure steam is produced in a fossil-fuel-fired boiler. The steam exhaust from the turbine (after electricity generation) can contain enough energy to be used in many industrial processes. This high back-pressure cogeneration system employs a coal-fired boiler modified to solve retrofitting space problems. The boilers generate high-temperature and high-pressure steam that powers a steam turbine to produce electricity. The exhaust steam can be used for space heating.

\section{Benefits}

\section{Energy Benefit}

The energy benefit of this technology is shown in Table 4.2 on page 4.4.

\section{A. 12}




\section{Environment}

There is no direct environmental benefit from this technology. However, the energy saved results in a reduction in the quantity of $\mathrm{SO}_{x}, \mathrm{NO}_{x}$, and $\mathrm{CO}_{2}$ released to the atmosphere. Performance is well below the established emission limits of the U.S. Environmental Protection Agency (EPA)

New Source Performance Standards.

\section{Quality}

None identified.

\section{Productivity}

The productivity benefit of this technology is the improved efficiency of power generation through cogeneration.

\section{Labor}

No new jobs have been created at the operating plant; however, job retention at the fuel supplier and the transportation supplier can be attributed to this technology. The industrial host can apply funds that would have gone into energy production improvements directly toward production improvements.

\section{International Competitiveness}

None identified.

\section{Current Status}

The unit at Burlington did not operate during FY 1991, as it was too small to justify necessary repairs. Cogentrix currently has sold 19 units; four of these were sold in 1992.

The strongest selling points of this technology have been the advanced combustion and environmental controls it uses. Local economic-development-related benefits, such as increased tax revenues, and job creation have also been positive factors.

Barriers that this technology has encountered include a certain amount of public skepticism and concern associated with the combustion of any fossil fuel in the United States today, which typically has to be overcome before any project can proceed toward successful implementation. Education programs as to the latest combustion technologies and what effect they may have on the environment are needed, according to one industry contact. 


\section{Cogeneration - Slow-Speed Diesel}

\section{General}

A cogeneration system based on a slow-speed diesel engine fired with residual oil has been developed to meet industrial steam and electricity requirements. Such a system could be installed in an industrial plant where the relation of electrical to thermal process-energy requirements is $20 \%$ or more.

\section{History}

A 23.3-MW cogeneration system that uses a slow-speed diesel engine was installed at HoffmannLaRoche Chemical Plant in January 1983. This unit has recently been downgraded to $22.6 \mathrm{MW}$ (the unit was de-rated for emission controls), but is still operating steadily at $95 \%$ capacity.

This unit was the result of a DOE cooperative agreement with Thermo Electron, Inc., of Waltham, Massachusetts, to design, build, install, and evaluate a diesel cogeneration system. The project was co-funded by DOE and Hoffmann-LaRoche. The purpose of the project was to verify cost savings expected to accrue from this type of system, using slow-speed diesel engines (which dominate the civilian marine propulsion field).

\section{Technology Description}

The system at Hoffman-LaRoche employs a two-stroke diesel engine fired with residual oil that drives an electrical generator. Exhaust gas from the engine is scavenged and used in a supplementary-fired, waste-heat boiler to generate the process steam. Waste heat from the engine-cooling circuits is also available to preheat boiler feedwater for other onsite boilers. The supplementary-fired waste-heat boiler, also fired with residual oil, is needed because the exhaust gas energy is insufficient to meet the plant's steam requirement.

\section{Benefits}

\section{Energy Benefit}

The energy benefit of this technology is shown in Table 4.2 on page 4.4. 


\section{Environmental Benefit}

There is no direct environmental benefit to this technology. However, the energy saved results in a reduction in the quantity of $\mathrm{SO}_{x}, \mathrm{NO}_{x}$, and $\mathrm{CO}_{2}$ released to the atmosphere.

\section{Quality Improvements/Technical Advantages}

None identified.

\section{Productivity Improvements}

None identified.

\section{Labor Improvements}

None identified.

\section{International Competitiveness}

None identified.

\section{Current Status}

In February 1983, two 20-MW diesel units and a 3-MW steam turbine were installed at the Sebring, Florida utility. This system is now only used for peaking capacity because of the high cost of diesel fuel versus the cost of coal. The utility purchases baseload electricity from other coal-fired baseload plants during nonpeak hours. The contact estimated that the system is required for approximately $35 \%$ of peaking operations. The contact also reported that system efficiency is probably $5 \%$ to $7 \%$ higher than when installed because of recent modifications to the diesel engines. No additional units were installed in 1993. Additionally, the steam cogeneration component of the system was not employed in FY 1992, as it required unjustifiably expensive repairs. As the system was only used to generate electricity with no added steam benefit, no energy savings will be attributed to the unit in 1993.

The industry contact for this technology could not be reached in 1993. The same energy savings figures reported in 1992 will be used for 1993. 


\section{Computer-Controlled Oven}

\section{General}

Solvent-based coatings are used in the production of automobiles, metal furniture, trucks, paper, fabric, metal coil, appliances, small metal parts, tapes, labels, and beverage cans. Coating processes typically result in volatile organic compound (VOC) emissions. Curing ovens are a major source of VOC emissions. The organic solvents or hydrocarbons in the coating are evaporated in the oven at temperatures ranging from $38^{\circ} \mathrm{C}$ to $370^{\circ} \mathrm{C}$. Because large volumes of air containing low concentrations of VOCs are involved, the fuel and investment cost of controlling these VOC emissions can be significant. Automatic control of vapor concentration in industrial finishing ovens permits operation with less diluted air. As a result, the amount of oven air that must be heated is reduced.

\section{History}

CENTEC received funding from DOE to develop computer-controlled solvent vapor concentration technology in paint-curing ovens. Analyzer Systems (previously Ryals Instrument Co.) purchased the marketing rights for the technology from CENTEC.

\section{Technology Description}

Although the number of sensors and types of auxiliary equipment are site-specific, the basic components and functions of the microcomputer-based control system are common to industry. Typical components include hydrocarbon sensors and analyzers, which measure the hydrocarbon concentration at various points within the oven, temperature sensors that monitor oven and incinerator temperatures, and pressure sensors that measure atmospheric pressure at several points in the oven. Microcomputer controller software and hardware collects information from the sensors, controls operating conditions, and presents such information using printouts, cathode ray tube (CRT) displays, and alarms. The technology optimizes the dilution of vapors in the curing oven's exhaust air.

Because great volumes of air containing low concentrations of VOCs are involved, the fuel and investment cost of controlling these VOC emissions can be significant. This technology controls these emissions. Automatic control of vapor concentration in industrial finishing ovens permits operation with less diluted air. As a result, the amount of oven air that must be heated is reduced. 


\section{Benefits}

\section{Energy Benefit}

The energy benefit of this technology is shown in Table 4.2 on page 4.4.

\section{Environmental Benefit}

Because the technology optimizes the dilution of vapors in the exhaust air, employee safety is enhanced and companies are able to meet current U.S. Environmental Protection Agency (EPA) regulations. All installed systems have implemented incinerators that reduce emissions of VOCs. Only the hydrocarbon content of the exhaust is monitored, therefore, it is not known if other pollutants are reduced. Though the reduction of emissions, in many cases, involves the optimization of air flows, which in turn reduces energy consumption, these systems are usually installed to meet state or federal EPA requirements. Fuel saved is usually natural gas, depending upon plant usage.

\section{Quality Improvements/Technical Advantages}

Improvement of product finish quality has been reported by some users, although no reason for this improvement has been proven.

\section{Productivity Improvements}

None identified.

\section{Employment}

Appears to be net zero.

\section{International Competitiveness}

None identified.

\section{Current Status}

No new units have been installed since the last unit was installed in September, 1991. A total of 15 units have been installed. None of the units were decommissioned during this reporting period. There have been no spin-off technologies developed as a result of this technology. 
The industry contact stated that the installation of a hydrocarbon analyzer does not always constitute the installation of a computer-controlled oven. Other applications include safety and emissions monitoring and solvent recovery.

The primary barrier this technology has encountered has been the cost of the system. Cost reduction and improved safety are the main selling points of the technology. 


\section{Energy Analysis and Diagnostic Center}

\section{General}

The DOE's Energy Analysis and Diagnostic Center (EADC) program mission is to analyze the operating characteristics and energy requirements of small- and medium-sized manufacturers to identify and recommend specific opportunities to conserve energy and/or uses of alternative energy sources through the conduct of energy audits.

\section{History}

The EADC program was initiated in 1976 with two EADCs and has grown to 18 EADCs. By the end of the 1991-1992 EADC reporting period, approximately 4,163 small- and medium-sized manufacturing plants have been aided by industrial energy audits. EADCs, located within accredited university engineering departments across the nation, are staffed by engineering faculty and graduate and undergraduate students who work under faculty direction.

\section{Technology Description}

An EADC audit team of four to six members conducts a one-day audit to analyze the energy use and manufacturing operations of the plant. The audit team prepares a list of energy conservation opportunities (ECOs) for the plant contact, who then identifies which of the ECOs will be implemented during the twoyear period following the audit. ECOs recommended by the EADC audits fall into six broad categories:

1. combustion equipment - efficiency changes, equipment maintenance and replacement, heat recovery, and confinement

2. steam equipment - upgrading, repair, and system changes

3. utilities and other energy forms - electricity, compressed air, water, fossil fuels, and purchased steam

4. scheduling equipment - plant scheduling, packaging, shipping, handling, and transportation

5. process equipment - maintenance, repair, replacement, operations and equipment process design, process heat recovery, and process heat confinement

6. building - lighting, space heating, space cooling, ventilation, and building grounds. 


\section{Benefits}

\section{Energy Benefit}

The energy benefit of this technology is shown in Table 4.2 on page 4.4 .

\section{Environmental Benefit}

The energy saved results in a reduction in the quantity of $\mathrm{SO}_{x}, \mathrm{NO}_{x}$, and $\mathrm{CO}_{2}$ released to the atmosphere.

\section{Quality Improvements/Technical Advantages}

None identified.

\section{Productivity Improvements}

None identified.

\section{Labor Improvements}

None identified.

\section{International Competitiveness}

None identified.

\section{Current Status}

In PNL's most recent conversations with University City Science Center (UCSC) (which has overseen the results of the EADC program) PNL was provided with the following information:

Beginning in the 1992-1993 period, field management of the EADC program is now provided by two regional field managers. UCSC manages the western region of the EADC program and the Office of Productivity and Energy Assessment of Rutgers University manages the eastern region of the program.

There are some minor differences between the data given to PNL previously during previous program years and the data provided in the TBRS table as a result of corrections and modifications made to UCSC's database of EADC results. UCSC continually updates and corrects the data in its database to maintain and improve its quality. One change that has had an impact in recent years has been the addition of operating 
and maintenance costs to energy conservation opportunities that recommend cogeneration. Another change has been a more accurate accounting of changes in energy consumption that result from cogeneration.

During EADCs 1992-1993 program year, 300 energy audits were conducted. Energy savings (by fuel type) associated with these audits are estimated as indicated in the following table:

\begin{tabular}{|c|c|}
\hline Fuel Type & $\begin{array}{c}\text { Millions of } \\
\text { Btu/year }\end{array}$ \\
\hline Electricity & 426,628 \\
\hline Natural gas & 559,826 \\
\hline Fuel Oil & 5,568 \\
\hline Coal & 0 \\
\hline Other & 135,143 \\
\hline Alternate & $-254,192$ \\
\hline Net & 972,973 \\
\hline
\end{tabular}

(Note: In 1993, contact with Charles Glaser at the Office of Industrial Technologies [OIT] revealed that OIT uses a 0.48 implementation factor for the EADC audits. This factor results an approximate 2.3 billion Btu/yr per audit energy savings. In 1993 PNL retroactively used a 0.50 implementation factor, in place of the 0.76 implementation factor used by UCSC.) 


\section{Energy-Efficient Canning}

\section{General}

This research did not result in the development of new hardware; instead, new applications were identified for existing hardware. Chief among these developments appears to be the application of hoods and steam jet vacuum compressors or heat exchangers to atmospheric cookers to reduce cooking energy losses in the food processing industry.

\section{History}

The DOE appears to have been involved as early as 1976 . DOE provided funding to the National Food Processors Association (NFPA) to identify energy losses at various unit operations within the canning industry. The energy losses identified from various cooker operations were primary targets for retrofitting or redesign. NFPA contracted three professors at the University of California-Davis to do the research. As part of the research, the retrofit designs were tested on actual production lines at Tri-Valley Growers Cooperative, Del Monte Corporation, and the now defunct California Canners and Growers. Since then, the industry has consolidated, some facilities and some plants have closed, and California Canners and Growers has gone out of business.

\section{Technology Description}

The equipment involved in the vapor-recycle retrofits and in new installations include an atmospheric cooker, a recycling steam jet vacuum compressor, a hinged hood, piping, and miscellaneous fittings. The steam jet vacuum compressor is the heart of the system. Part of the incoming steam furnishes the vacuum to draw the vapor from the headspace, compress it, and reintroduce it at the front end of the cooker. The other retrofit involves a recirculation pump and heat exchanger that can be installed on individual cookers or on a series of cookers, depending on the plant layout. Instead of condensing steam inside the retort, an outside heat exchanger is used to heat water under more controlled conditions. Water heated in the heat exchanger is circulated through the retort.

\section{Benefits}

\section{Energy Benefit}

The energy benefit of this technology is shown in Table 4.2 on page 4.4. 


\section{Environmental Benefit}

Atmospheric cooker retrofits reduce $\mathrm{CO}_{2}, \mathrm{SO}_{x}$, and $\mathrm{NO}_{x}$ emissions as a result of energy savings. Recirculated heat exchanger or thermal syphon atmospheric cookers reduce steam usage by at least $30 \%$. Reducing steam usage means less natural gas or fuel oil has to be burned to produce steam.

\section{Quality Improvements/Technical Advantages}

None identified.

\section{Productivity Improvements}

None identified.

\section{Labor Improvements}

None identified.

\section{International Competitiveness}

None identified.

\section{Current Status}

This is the second year that this technology has been tracked. Last year, information from Tri-Valley Growers suggested there were 36 retrofitted atmospheric cookers operating at Tri-Valley plants in 1991. This year's contact with Tri-Valley Growers revealed that the total number of cookers operating with a retrofit was down to 29. Last year Tri-Valley estimated they had 18 cookers with the thermal syphon recycle retrofit and 18 with the recirculation pump and heat exchanger retrofit. This year Tri-Valley indicated they had no thermal syphon recycle retrofits operating and that the number from last year was an estimate for the California Food Industry. While Tri-Valley's number of thermal syphon retrofits was reduced this year, their number of heat exchanger retrofits increased from 18 to 29 .

The heat exchanger retrofit has certain characteristics that make the energy savings very difficult to track. The retrofit can be accomplished with any of a number of brands of generic tubular of plate heat exchangers. There is not a single unique firm that specializes in producing heat exchangers, especially for this application. As a result, this retrofit will not be actively tracked; if, through future contacts with industry similar retrofits are identified, then the savings will be counted. 
Unlike the heat exchanger retrofit, the thermal syphon recycle retrofit uses a key component that is produced by a single firm; thus tracking sales of this technology is much easier and more direct. Pardee Engineering, the manufacturer of the major component of the thermal syphon recycle retrofit (a recycling steam jet vacuum compressor), provided a customer list late last year. It indicates at least 76 units have been sold for retrofit cooker applications. To generate a conservative energy savings estimate, these 76 units will be assigned evenly to each year, from 1981 to 1992 . Since no installation dates are available, this approach seems appropriate and conservative given the contact's assertion that most of the units were sold by the mid-1980s. During the past two years, Pardee estimated that about 10 ejectors were sold for cooker retrofits; Pardee also indicated that some units are replacements for existing retrofits. To be conservative, it will be assumed that half the units are replacements rather than new installations; thus, only five new ejectors will be added to the energy savings calculation this year.

FMC operation, a major manufacturer of atmospheric cookers, offers the hood/ejector retrofit as an option on its line of new cookers. However, FMC has been unwilling to provide information regarding unit sales. NFPA representatives estimate that FMC produces over $90 \%$ of the atmospheric cookers used in the food processing industry. Estimates of the number of atmospheric cookers operating in the United States range anywhere from 200 to 2,000 . One industry contact indicated that the only barrier to adding more retrofitted atmospheric cookers is that boiler steam costs have been reduced because of the $50 \%$ drop in natural gas and fuel oil prices since 1980. Retrofit capital will only be spent if an acceptable payoff exists. It might be worth DOE's time to fund a small study to determine what the payback period is under current fuel prices. In the past, these units could pay for themselves in one season. 


\section{Ethanol from Food Wastes}

\section{General}

A new, continuous, low-cost, low-energy process for the production of ethanol from sugar, molasses, starch, or cellulose is nearing large-scale production tests. The process combines fermentation and ethanol separation within the same reactor. The immobilized cell reactor separator (ICRS) technology was developed at Purdue University (Purdue).

\section{History}

Since its conceptualization and patenting in 1983, refinements, process design efforts, and scale-up studies have been ongoing at Purdue, funded by DOE and the Wisconsin Milk Marketing Board. A prototype unit at the Allen Dairy in Ft. Wayne, Indiana, has been taken out of service but provided valuable operating experience and demonstrated the technology's feasibility. In September of 1991, Purdue contacts indicated that two other dairies planned to install full-scale units that will treat $100 \%$ of their waste cheese whey. At that time, it was expected that both units would be constructed and operating within six to nine months.

\section{Technology Description}

The ICRS consists of a fermentation tower into which the fermentable sugars are fed on a continuous basis. A high concentration of microbes are immobilized on an absorbent matrix within the towers. This high cell density ( 30 to $70 \mathrm{~g}$ of cells-dry basis/l reactor compared with a maximum of about $2 \mathrm{~g} / \mathrm{l}$ in a batch) causes the fermentation to proceed immediately at a rate 15 to 25 times faster than conventional batch fermentations. A gas stream is circulated through the towers to pick up the ethanol as it is formed within the fermentors. The ethanol then leaves the ICRS system as a vapor and is recovered and concentrated. Combining ethanol separation with high-rate immobilized cell fermentation, further speeds the fermentation as ethanol is both inhibitory and toxic to the organisms, and the ethanol separation allows more highly concentrated feeds to be completely fermented. The technology will produce a $60 \%$ pure ethanol stream at a rate of $1 \mathrm{gal} / \mathrm{yr}$ per gal/day milk capacity (e.g., a 100,000-gal/day dairy will produce $100,000 \mathrm{gal} / \mathrm{yr}$ of $60 \%$ ethanol), which can then be refined to $95 \%$ to $100 \%$ ethanol for subsequent use.

Although a large dairy would be classified as a small ethanol producer compared with commercial ethanol producers, the ethanol may displace fuel used at the dairies by substituting it for a portion of the gasoline used in the farm equipment. Displacing 100,000 gal of gasoline each year with ethanol would save about 7.8 billion Btu/yr. (Note: This is much more than would be used by one farm, particularly if a gasoline/ethanol mixture was being used with only $10 \%$ ethanol.) The real savings to the dairies result 
from the avoidance of fees that are normally incurred from releasing waste carbohydrates into the municipal sewage system or from paying landfill disposal costs. The energy savings from this technology is $20,000 \mathrm{Btu} / \mathrm{gal}$.

\section{Benefits}

\section{Energy Benefit}

The energy benefit of this technology is shown in Table 4.2 on page 4.4.

\section{Environmental}

The United States produces approximately 50 to 60 billion $\mathrm{lb}$ of cheese whey each year, only $45 \%$ of which can be used by the dairies for other purposes. The remainder of the cheese whey must be disposed of by some means.

\section{Quality}

None.

\section{Productivity}

None.

\section{Labor}

This technology has the additional appeal to industry of being a continuous, low-labor process. This technology has not impacted employment to date.

\section{Current Status}

A pilot plant began test operation in 1993 in Hopkinton, Indiana, at Permate Refining, Inc. Testing of this facility yielded successful results, and operation will continue into 1994 . This plant has a capacity of $300 \mathrm{gal} / \mathrm{yr}$ and consumes $15,000 \mathrm{Btu} / \mathrm{gal}$ of anhydrous ethanol, compared with 35,000 to $60,000 \mathrm{Btu} / \mathrm{gal}$ energy consumption by current technologies (depending on which technology is employed). This appears to be the first commercial installation for the ICRS technology. The major barrier that this technology faces is industry's unwillingness to commit until they see a working full scale plant before they invest. Another barrier expressed by the industry contact is the depressed condition of the dairy industry (i.e., no 
cash for nonessential projects). Because this technology has not yet generated significant energy savings, it will continue to stay on the emerging technology table and be tracked for future energy savings. 


\section{High-Efficiency Weld Units}

\section{General}

Cyclomatic Industries, Inc., developed a new power supply design that is used for arc welding. It is smaller, lighter, and significantly more energy efficient than conventional arc welding.

\section{History}

Using solid-state electronics known as "inverter technology," a 250-amp prototype power supply weighing $65 \mathrm{lb}$ was developed. This prototype is capable of operating with a nominal efficiency range of $80 \%$ to $91 \%$ and a power factor of near unity, compared with 0.5 to 0.8 for conventional units. Use of the system allows a greater degree of control over the welds produced, thereby enhancing weld quality.

This arc welding power supply can be used for all arc welding processes. It can also be used in plasma cutting applications. Several manufacturers of welding power supplies are offering units, and sales in the last few years have been so significant that they are displacing the market share of conventional welding equipment.

\section{Technology Description}

The new weld units deliver a current at powerline voltage directly to a silicon-controlled rectifier, which converts the standard $60-\mathrm{Hz}$ alternating to direct current. An inverter then reconverts the power to alternating current but at a much higher frequency $(1,000$ to $5,000 \mathrm{~Hz})$. Next, a transformer steps down the voltage to the appropriate range. Finally, in a second rectifier, the current is again converted to direct current for welding.

The energy benefit of this technology is derived from the superior power factor achieved by the weld units. Power factor is the fraction of the amount of power capable of performing work relative to the total complex power. Utilities typically charge their customers for low power factors.

\section{Benefits}

\section{Energy Benefit}

The energy benefit of this technology is shown in Table 4.2 on page 4.4 . 


\section{Environmental Benefit}

One environmental benefit of this technology is reduced electrical consumption a result of its being significantly more energy efficient than conventional power supplies. There is also less energy required (12 lb of silicon steel rather than 150 to $200 \mathrm{lb}$ of copper). The units take up less space and are also portable, reducing the need for forklifts or cranes to move the units.

\section{Quality Improvements/Technical Advantages}

Improved welding arc characteristics reduces spatter (the clean up) of heat-affected zones (there is less distortion of thin materials).

\section{Productivity Improvements}

Construction site use, shipboard use, and maintenance all report reduced energy consumption and reduced equipment need (loaders, forklifts, cranes, etc.) for loading/moving purposes. This multi-process reduces the need for additional power sources.

\section{Employment}

Not known.

\section{International Competitiveness}

One fourth of all the units sold have been overseas.

\section{Current Status}

The National Electric Manufacturers Association (NEMA) conducts an annual survey of electrical equipment sales. In 1993, NEMA reported U.S. sales at 8,900 units. Overseas sales were approximately $25 \%$ of U.S. sales. Additional data from direct contacts with industry representatives for FY 1992 are listed in Table 4.2. Sales of commercial units in FY 1993 were up slightly from FY 1992. There are currently over 40,000 units operating in the United States.

The greatest barrier in the sale of this technology has been its price, which is at a $15 \%$ to $20 \%$ premium over conventional equipment. The strongest selling points of this technology are its superior size, weight (portable), and multi-process use. 


\section{Hyperfiltration - Food}

\section{General}

Hyperfiltration has been applied in the food industry as a membrane-based separation processing approach that can be used to preconcentrate fruit juice prior to evaporation, leading to thermal energy savings.

\section{History}

The DOE funded the National Food Processors Association (NFPA) to develop energy-efficient separation and concentration processes for food (juice) products. The objectives were to reduce processing, preservation, containerization, and transportation energy requirements and costs.

Research has determined which class of membranes presently available could be used in the fruit and vegetable juice processing industry. Applying membranes in this industry reduces the reliance upon evaporators or distillation equipment normally required to remove large quantities of water from the juice before it is stored or transported.

NFPA demonstrated this new technology and installed units but did not develop a unique membrane. Energy savings associated with additional units, therefore, cannot be easily linked to DOE. The numbers reported are the energy savings for the original units that were installed because of NFPA's program.

\section{Technology Description}

Hyperfiltration, or reverse osmosis, is a pressure-driven, membrane-based separation technique for concentration or purification of solutions. A purified permeate and a concentrated retentate are produced from a feed solution. This process can be applied to separate fruit juice into serum and pulp, concentrate the serum to a self-preserving solids level, and recombine by homogenization. The major selling points of the technology are the energy savings resulting from de-watering (reducing the load on the evaporator), a potential increase in plant capacity (if the plant evaporator had been operating near capacity), and an improvement on product quality. 


\section{Benefits}

\section{Energy Benefit}

The energy benefit of this technology is shown in Table 4.2 on page 4.4.

\section{Environmental Benefit}

By reducing the amount of water in fruit concentrate, energy and cost savings are achieved in processing, containerization, and transportation. The environmental benefits from these savings include smaller amounts of energy used and emissions in processing. As the need for an evaporator is reduced, fewer packaging materials may end up in land fills, and fewer emissions will result because of less transportation.

\section{Quality Improvements/Technical Advantages}

A quality improvement is realized due to less exposure of the product to high temperature conditions in the evaporator.

\section{Productivity Improvements}

The use of this technology facilitates increased plant capacity, particularly if the evaporator of a plant had been operating at or near capacity. The reverse osmosis system can remove significant quantities of water (around $50 \%$ ) before being sent to the evaporator, where the remaining water is removed to the desired solids level.

\section{Labor Improvements}

None identified.

\section{International Competitiveness}

In 1988, one unit was installed in the Philippines. This unit has been included in the energy savings calculations since that time.

\section{Current Status}

The application of membrane systems in the fruit processing industry (as well as in the dairy industry) began several years ago, and several hyperfiltration units have been installed during the last few years. 
However, energy savings for this study have been calculated from information provided by vendors of the original units that were installed as a result of NFPA's program.

One unit was installed in 1993 in California. 


\section{Hyperfiltration - Textiles}

\section{General}

DOE helped demonstrate hyperfiltration systems in recycling hot water and reconstituting dye formulation from dye-range wash water in the textile industry.

\section{History}

Carre, Inc. (recently acquired by DuPont Separation Systems), coupled a method for manufacturing porous, stainless-steel tubes with a DOE technology to form a metal-oxide (e.g., zirconia) membrane in place along the interior of the tube. Through the program, use of a prototype unit was successfully demonstrated in South Carolina, showing energy savings resulting from the reuse of dyes and from the reduction in energy required to treat the wastewater. Had it not been for DOE's initial support of the demonstration project, an industry contact stated that membrane technology might not have been used in the textile industry for treatment of wastewater. The demonstration unit has since been decommissioned.

\section{Technology Description}

Hyperfiltration is a pressure-driven membrane separation technique that has been used effectively to desalinate seawater. Membranes that have been successful in desalination but are not applicable to many hot and dirty industrial wastewaters. New membranes and systems were required for this project.

The development of hyperfiltration membranes has been motivated by the fact that only a small amount of energy is required to separate water and dissolved solutes. The energy needed to operate a hyperfiltration process is much less than the energy that can be recovered from a hot waste stream. In the application of hyperfiltration to textile dying, heated wash water is processed and recycled, and dyes and chemicals are separated from the water and reused. Significant savings in materials and energy result.

\section{Benefits}

\section{Energy Benefit}

The energy benefit of this technology is shown in Table 4.2 on page 4.4. 


\section{Environmental Benefits}

The application of this technology benefits the environment in a number of ways. Hyperfiltration obliviates the need for filter media that would have been employed in the acid neutralization process, as well as diatamaceous earth (as in the case of the corn sweetener industry). This results in a reduction of landfill requirements.

\section{Quality Improvements/Technical Advantages}

Product quality improvements are not well quantified. Preliminary reports indicate that cleaner downstream process steps result from the use of hyperfiltration.

\section{Productivity Improvements}

There is no data to indicate if productivity improvements are achieved through the use of this technology.

\section{Labor Improvements}

Approximately 50 jobs have been created for the engineering and manufacturing of the units. The technology has had no job loss/creation effect in plant operations.

\section{International Competitiveness}

Since 1980, three units have been sold overseas:

- one polyvinyl alcohol recovery unit in Taiwan

- one 75 gpm textile dye water recycle unit

- one 35 gpm wool scour water recycle unit.

To the best of DuPont's knowledge, all of the overseas units are still in use.

\section{Current Status}

Six large units are operating, as well as several smaller units. Two new polyvinyl alcohol recovery units have been installed in 1993, in Virginia and South Carolina. To date, no units have been shut down. 
Clarification of the number of U.S. installations has revealed that five units (in addition to the demonstration unit) have been installed in the United States. One unit recovers caustic in a South Carolina plant; another unit installed in North Carolina recovers polyvinyl alcohol. Two new units were sold in 1991 for chemical recovery purposes. A facility in Georgia is employing this technology for hazardous waste volume reduction. Two other plants (one in Iowa, another in Illinois) are employing this technology to clarify corn sweeteners. Although not textile-related applications, the technologies employed in these two operation were developed by DOE and Carre, Inc.

The diffusion of this technology has been greatly impacted by lack of enforcement of federal regulations affecting the disposal of wastes. This technology was initially developed, in part, in response to the zero discharge rule of 1979 . Since that time, these regulations had been relaxed, directly impacting the sale of these units. Stronger environmental enforcement or additional tax credits would assist in sales. Recent regulations affecting hazardous waste disposal, however, have stimulated sales in this unexpected new market. The strongest selling points for DuPont's units have been their durability and ruggedness in an industrial setting. 


\section{Improved Diesel Engines}

\section{General}

A new technology appears to be one of the Technology Benefits Recording System's (TBRS's) largest energy savers. The fuel efficiency of heavy diesel engines has been improved, in part as a result of DOE financial support.

\section{History}

A diesel engine working group was formed in 1979 as part of the Energy Conservation and Utilization Technologies (ECUT) Division's Combustion Technology Program. The group continued under the Advanced Industrial Concepts Division (AICD). AICD's Combustion Technology Program guided the development and application of diagnostic tools and computer models to study critical diesel engine combustion processes.

\section{Technology Description}

U.S. diesel engine manufacturers are applying the tools and models developed by the Combustion Technology Program to improve present engines and develop advanced diesel engine designs. Cummins Engine Company (the U.S. market leader) has used KIVA, a multi-dimensional model that numerically simulates diesel fluid mechanical and combustion processes, to assess combustion chamber shapes and piston designs for next generation products. Use of KIVA resulted in piston design modifications and other modifications to Cummins' diesel engines. Cummins has also improved engine breathing, pulsepreserving manifolds, and the design of turbochargers.

\section{Benefits}

\section{Energy Benefit}

The energy benefit of this technology is shown in Table 4.2 on page 4.4 .

\section{Environmental Benefit}

Cummins continues to develop an understanding of nitrogen-oxide and soot controls in diesel engines. Through the combination of DOE-sponsored analytical and experimental research, Cummins continues to 
increase their understanding of in-cylinder emissions control. This work has been, and will continue to be, incorporated into the combustion chamber design work at Cummins.

\section{Quality Improvements/Technical Advantages}

None identified.

\section{Productivity Improvements}

None identified.

\section{Labor Improvements}

None identified.

\section{International Competitiveness}

None identified.

\section{Current Status}

A major contributor to the working group was the Cummins Engine Company. Cummins has accumulated a great deal of knowledge, skill, and experience to become the world's leading manufacturer (currently more than $50 \%$ of the U.S. market) of diesel engines for heavy trucks. According to Cummins, improvements to the engine account for an approximate $0.45 \mathrm{mpg}$ increase in the typical $1970 \mathrm{~s}$ diesel engine. Based on information available and conservative assumptions, PNL has estimated the annual savings resulting from the engine improvements alone to be about 45 trillion $\mathrm{Btu} / \mathrm{yr}$. 


\section{Kalina Cycle Heat Transfer}

\section{General}

The DOE, in cooperation with Exergy, Inc., of Hayward, California, has developed an energy-saving family of alternative power systems employing the Kalina cycle, which can improve the plant efficiency of thermal power plants by $15 \%$ to $30 \%$. The Kalina cycle is an alternative to the standard, or steam, cycle (by which approximately $70 \%$ of all electric power is generated).

\section{History}

The demonstration of the Kalina cycle by Exergy has taken place at DOE's Energy Technology Engineering Center (ETEC) at Canoga Park, California. The facility is operated for DOE by Rockwell International. The Kalina cycle was invented by Dr. Alexander Kalina. It is designed to overcome shortcomings of the traditional Rankine cycle to dramatically increase the efficiency of power generation systems.

\section{Technology Description}

In the standard cycle, water is converted to vapor under high pressure in a boiler, then expanded through a turbine to generate electricity. The spent vapor is condensed, pumped, and returned to the boiler. The use of a single, working fluid forces a compromise between the disparate requirements, resulting in significant energy loss.

The Kalina cycle technology is based on the new concept of changing the working fluid in different parts of the system, thus avoiding the compromise required in the standard steam cycle. This is achieved by using a working fluid which is a mixture of two or more components, and varying their ratio. Energy losses are drastically reduced and efficiency is increased; from the same quantity of fuel, more electricity is produced.

\section{Benefits}

\section{Energy Benefit}

The energy benefit of this technology is shown in Table 4.2 on page 4.4 . 
The Kalina cycle is $15 \%$ to $25 \%$ more efficient overall in power production relative to baseline Rankine cycle steam generation facilities. Approximately $70 \%$ of all power generated in the U.S. employs the less efficient Rankine cycle technology. If all these facilities switched to the Kalina cycle, approximately $\$ 6$ billion (at 1991 prices) would be saved annually in power production.

\section{Environmental}

The use of this technology results in a secondary emissions reduction of $15 \%$ to $25 \%$ (linear with fuel savings).

\section{Quality}

Relative to Rankine cycle plants, Kalina cycle facilities offer a high-performance, reliable, and low emissions alternative.

\section{Productivity}

The use of this technology ultimately results in a lower cost of electricity to the end user.

\section{Labor}

Approximately five Energy staff are employed at the demonstration plant in Canoga Park.

\section{International Competitiveness}

None identified.

\section{Current Status}

This technology has been successfully demonstrated at the DOE facility in Canoga Park and is ready for commercialization. Exergy will lead the commercialization effort; however, a number of barriers must be overcome before the technology can be commercialized. The power industry is risk averse, the technology must be shown to be effective, and some incentive must be employed to encourage industry to adopt the technology. Because a utility's return on investment is often set by a public utility commission, little incentive exists for pioneering new technology. Banks are less willing to lend against unproven technologies without guarantees of performance, schedule, and price. As this technology has not yet generated significant energy savings, it will continue to stay on the emerging technology table and be tracked for future energy savings. 


\section{Membrane System for Purified Gas Production}

\section{General}

A/G Technology Corporation developed a membrane system for purified gas production. This membrane system was developed for the purpose of enhancing the oxygen content of the air stream to industrial furnaces. Production of oxygen through the system does not result in energy savings, pound for pound, as compared with conventional large-scale cryogenic oxygen production. Customers save costs such as shipping and rental, which can be substantial for distant locales. Other advantages to the system may also dictate use in various applications.

\section{History}

DOE contracted with CS Systems to develop a chemical separation system that uses fluid extraction. The system would recover organics and effluents, as well as be more energy efficient than previous systems.

\section{Technology Description}

A hollow fiber membrane system was developed by A/G Technology for the purpose of enhancing the oxygen content of the combustion air stream to industrial furnaces. A single cylinder of the system contains many small tubes of proprietary polymer that separate oxygen and nitrogen from other constituents in air. The units are modular so that a range of application sizes are possible by connecting several units in parallel. The system produces a gas stream containing $35 \%$ oxygen, which is usable in a number of applications. A/G Technology has since adapted the system to produce purified nitrogen streams containing $90 \%$ to $95 \%$ pure nitrogen. The many advantages include units that are portable, require little maintenance, operate on compressed air, and avoid additional cost such as rental, delivery, and storage of gas cylinders. Production of oxygen through the system does not result in energy savings that are pound for pound less expensive, as compared with conventional large-scale cryogenic oxygen production.

\section{Benefits}

\section{Energy Benefit}

The energy benefit of this technology is shown in Table 4.2 on page 4.4 . 


\section{Environmental}

The environmental benefits of this technology are somewhat limited. Two environmental benefits of this technology are the reduced emissions from the membrane system process and the avoided emissions from vehicles that would be delivering bottled gas to facilitates.

\section{Quality}

No quality impact of this technology has been identified.

\section{Productivity}

No productivity impact of this technology has been identified.

\section{Labor}

No labor impact of this technology has been identified.

\section{International Competitiveness}

Three of these units have been sold overseas to date.

\section{Current Status}

To date, A/G Technology has sold approximately 47 units that separate oxygen and nitrogen from an air stream. Five of these units were sold in 1993, and three of the units were sent overseas.

Although no energy savings benefit exists for this technology, it will appear in Table 4.2 for the 1993 Benefits Report. A note in the electronic version of the table explains the absence of an energy saving figure. 


\section{Methanol Recovery Process}

\section{General}

Spent methanol was the largest hazardous waste at FMC Corporation's Bayport plant. Methanol is used to regenerate a catalyst in the hydrogen peroxide purification process. Their generation process utilizes methanol as a solvent for the organics and in the process generates spent methanolis.

\section{History}

All hydrogen produced in North America is produced by organic process (O-Process). In this process, quinones are carried in the recycling mixture of organic solvents known as the work solution. The quinones are alternately reduced and oxidized to form hydrogen peroxide. The hydrogen peroxide is removed from the recycling work solution via a liquid-liquid extraction with deionized water. This resultant crude peroxide is purified and then concentrated in distillation columns to the desired shipping concentration.

\section{Technology Description}

Steam distillation is a method of distillation in which stream is injected in the distillation column. This is in contrast to traditional distillation, where steam or another heat source is indirectly applied through an external reboiler. Using steam sparged into the distillation column to distill the methanol versus a reboiler prevents the buildup of undesirable quantities of hydrogen peroxide and metal cations. Concentration of hydrogen peroxide and metal cations in the bottom of the methanol distillation column presents two hazards. The first hazard is the generation of oxygen from the decomposition of hydrogen peroxide by metal ions with the potential of methanol fire or explosion. The second hazard is the concentration of hydrogen peroxide to a sufficient strength, leading to a violent decomposition or detonation (reaction catalyzed by metal ions). The steam distillation systems will prevent the concentration of the peroxides and metal ions, allowing the methanol to be recovered efficiently and safely. The condensing steam in the bottom of the column will act as a dilutant, preventing any concentration of undesirable components.

\section{Benefits}

\section{Energy}

The energy benefits of this technology are quite substantial. Based on recent methanol usage rates at the FMC's hydrogen peroxide plants, 320,000 gal of fresh methanol are used per year. The recovery 
scheme recovers $278,000 \mathrm{gal}$ of this methanol. The energy required to produce 278,000 gal of methanol from natural gas is 27.45 billion Btu/yr. Reducing fresh methanol deliveries by $90 \%$ and eliminating the hauling of spent methanol to an incinerator will result in a savings of 1.68 billion Btu/yr in energy for transportation. Eliminating the need to incinerate the spent methanol will result in a savings of fuel used when burning the methanol. At present, no data is available on the amount of fuel used to incinerate methanol, so this savings cannot be determined. The amount of energy required to recover the methanol via steam distillation is 10.916 billion Btu/yr. This will result in a net energy savings of 18.214 billion Btu/yr.

\section{Environmental}

The primary environmental benefit of this technology is the reduction of air emissions. Air emissions are reduced by not having to incinerate $320,000 \mathrm{gal} / \mathrm{yr}$ (or $2,105,242 \mathrm{lbs} / \mathrm{yr}$ ) of methanol. Emissions are also reduced by the elimination of tanker trips from the plant to the incinerator.

\section{Quality}

No quality impact of this technology has been identified.

\section{Productivity}

No productivity impact of this technology has been identified.

\section{Labor}

No labor impact of this technology has been identified.

\section{Current Status}

To date, two units have been installed. Plans to install additional units within FMC Corporation have been placed on hold. FMC has no interest in selling the technology. 


\section{Methane Enrichment Digestion}

\section{General}

In a joint venture funded partially by the National Renewable Energy Laboratory (NREL), engineers have produced "pipeline-quality" natural gas directly from garbage. This was accomplished at the Reedy Creek Utility District at Disney World near Orlando, Florida. The technology has the potential to substantially reduce the cost of refining high quality methane from solid waste, using technology that is compatible with solid waste digestion systems around the country.

\section{History}

Work on the new digester technology demonstrated at Disney World was initiated by the Gas Research Institute of Chicago and was carried out by the Institute of Gas Technology (also in Chicago) and the University of Florida, with major funding from NREL and the State of Florida.

\section{Technology Description}

Standard industrial anaerobic digesters produce gas that is roughly $55 \%$ methane and $45 \%$ carbon dioxide. However, the gas must be about $95 \%$ methane to be used commercially in heating, cooking, or transportation. This technology involves modifying the anaerobic digester to remove the carbon dioxide and to leave a gas that is up to $95 \%$ methane.

Producing pipeline-quality gas eliminates the need for more costly methods normally used by the gas industry and chemical industries to remove carbon dioxide from landfill gas.

\section{Benefits}

\section{Energy Benefit}

The energy benefit of this technology is shown in Table 4.2 on page 4.4. 


\section{Environmental}

In addition to the indirect environmental benefits (reduced emissions) resulting from the energy savings of this technology, the use of this technology promotes the use of organic wastes and energy crops, which in turn reduces the use of fossil fuel in the United States. Such fuels produce a variety of greenhouse gases. Methane combustion produces only $10 \%$ of the quantity of these gases produced by fossil fuel combustion.

\section{Quality}

This technology removes any methane or carbon dioxide from the landfill gas. Similar technologies remove only the carbon dioxide portion.

\section{Productivity}

Although this technology does not produce a higher yield of methane than competing methane production technologies, it does reduce the amount of production loss from approximately $10 \%$ to near $3 \%$. The higher methane content of the gas produced results in a greater energy (Btu) content.

\section{Labor}

No labor benefit of this technology has been identified.

\section{International Competitiveness}

None identified.

\section{Current Status}

To date, no units have been sold; however, three firms have expressed interest in this technology. One of these firms has almost completed a licensing agreement with the Gas Research Institute. The firm has developed a business plan for the commercialization of this technology and has plans to construct a commercial-scale facility.

As this technology has not yet generated significant energy savings, it will remain on the emerging technology table and will be tracked for future energy savings. 


\section{Nitrogen-Methanol Carburization}

\section{General}

Air Products and Chemicals developed a system for producing the nitrogen- and carbon-rich atmospheres used in heat treating of metals that injects controlled amounts of nitrogen and methanol into the heat-treating furnace and avoids the use of a conventional, natural gas-fired atmosphere generator. Not only are savings in natural gas achieved, but much better control of the atmosphere is attained and system operating safety is increased.

Savings for individual installations can vary greatly, depending upon both known and unknown parameters. Examples of relatively well-known parameters include annual average hours of operation, average size of furnace, number of furnaces per customer, etc. Unknown parameters include the degree of furnace control exerted by the operator, actual throughputs through the furnace, and "airtightness" of the furnace. In the past, there has been confusion regarding what was meant by an installation, unit, site, etc. As a result, uniform "rules of thumb" were used to determine the number of endothermic generators replaced by the nitrogen methanol systems, and energy savings were based on the number of generators replaced. This year a nitrogen-methanol unit was defined as one nitrogen-methanol panel per furnace. This one-to-one ratio between furnaces and nitrogen-methanol units or panels was verified by industry contacts. There are exceptions to this ratio, but the majority of nitrogen-methanol panels installed control only one furnace. With the new methodology, an energy savings per furnace figure has been developed that can be multiplied by the number of furnaces in operation for a given year.

\section{History}

Eight companies that had been known to be involved with U.S. installations of the nitrogen-methanol carburization technology have been contacted during the past several years. Information from these nitrogen-methanol manufactures indicated a decrease in the total number of furnaces operating in 1991. Marketers estimated in 1991 that this technology has achieved about $25 \%$ to $30 \%$ penetration in the atmospheric heat treatment industry.

In FY 1992, the industry contacts cited the economic slump, the low price of natural gas relative to methanol, stiffer methanol storage regulations, and superior controls now available on endothermic generators as factors that have led to slower sales for this technology. 


\section{Technology Description}

Carburization is a two-phase, heat-treating process in which steel parts are maintained at high temperatures in a furnace filled with a carbon-containing atmosphere; the process produces a case-hardening effect that improves strength, hardness, and wear resistance. Traditionally, in an endothermic process, air and natural gas are reacted (by heating each in a furnace) to produce an atmosphere containing $20 \%$ carbon monoxide, $40 \%$ hydrogen, and $40 \%$ nitrogen. Carbon from this atmosphere is absorbed into the steel. In a second phase, the carbon concentration at the surface of the steel approaches the concentration of the carbon in the atmosphere. The speed of the second phase of carburization depends on the speed at which the carbon is diffused into the steel. Natural gas is consumed in this process both as a reactant inside the generator as well as a fuel for heating the furnace.

Nitrogen-methanol carburization employs pure methanol enriched with natural gas to form a carburizing atmosphere that is approximately one-third carbon monoxide and two-thirds hydrogen. The higher concentrations of carbon monoxide and hydrogen accelerate the rate of the first phase of carburization. Reduced heating times required for this process results in energy savings between $7 \%$ and $17 \%$.

\section{Benefits}

\section{Energy Benefit}

The energy benefit of this technology is shown in Table 4.2 on page 4.4 .

\section{Environmental Benefit}

Nitrogen-methanol atmosphere systems are used in the heat-treating industry for carburizing, neutral hardening and, to a certain extent, annealing. We have not studied the environmental impact of nitrogenmethanol systems because the atmosphere is similar to that produced by conventional means, i.e., endothermically generated atmospheres with a composition of $20 \%$ carbon monoxide, $40 \%$ hydrogen, and $40 \%$ nitrogen.

A possible environmental benefit is an overall reduction in the volume of atmosphere used. When a customer converts to a nitrogen-methanol system, they generally are able to reduce their atmosphere production because systems do not create excess atmosphere capacity. In contrast, endothermic generators have limited turn-down capability, which often means that excess capacity is combusted to carbon dioxide and water vapor before being vented to the environment.

Fuel savings may not be significant. In order for an endothermic generator to produce atmosphere, it must be externally heated by electricity or a fuel gas. This is not a requirement of nitrogen-methanol systems. On the other hand, methanol requires a certain amount of heat for vaporization and dissociation, 
which is typically provided by the furnace into which it is injected. Thus, the furnace's heat input requirement is increased with the use of nitrogen-methanol systems.

\section{Quality Improvements/Technical Advantages}

Quality improvements are possible for two situations. The first improvement is the replacement of old, maintenance-prone generators that tend to fail during heat treat cycles, potentially ruining the parts in the furnace. The second improvement is the heat treating shops that, for whatever reason, do not provide the necessary preventative maintenance and operational control of their generators. The result tends to be inconsistent atmosphere composition and reduced product quality. Nitrogen-methanol systems require less maintenance and attended operation than generators.

\section{Productivity Improvements}

The primary benefit is negligible start-up times for nitrogen/methanol systems. In contrast, endothermic generators require several hours for heat-up and conditioning before they are capable of producing an acceptable atmosphere.

\section{Employment}

None identified.

\section{International Competitiveness}

None identified.

\section{Current Status}

The market for this technology appears to be flat. According to those contacted in 1993, only 16 units were installed since September 1992; no units were reported as decommissioned, however. Reasons that were given were that the units have a long life and are reliable. Also, it takes a significant capital investment to switch back to endothermic generators. Apparently, hundreds of units have been sold overseas. One contact said that the United States represented only about $10 \%$ of their world-wide sales. No details were given, however, as to exactly how many, what size, what years sales were made, or the location. A significant amount may have been installed in China, Korea, and Scandinavian countries.

Historically, operational cost has been the strongest barrier to commercialization of nitrogen-methanol systems. Even though noncryonic nitrogen supply schemes have lowered the cost of nitrogen, the cost of methanol is too high for nitrogen-methanol to compete economically with endothermic generators on a unit atmosphere cost basis (i.e., dollars per hundred cubic feet). 
A new challenge to nitrogen-methanol systems might become more common. The enactment of the Code of Federal Regulations (CFR) 1910.119 imposes stringent record-keeping requirements on users of flammable liquids which are stored onsite in one location, in a quantity of $10,000 \mathrm{lb}$ or more. For methanol, this would be equivalent to $1,500 \mathrm{gal}$. Heat treaters currently using or considering conversion to nitrogen-methanol systems will have to decide if the cost of compliance outweighs the benefits of nitrogenmethanol. It is possible that current systems may become decommissioned and that plans for new installations will be curtailed.

The strongest selling points of this technology have been the following:

- no wasted atmosphere,

- more consistent atmosphere composition resulting in improved product quality,

- less downtime caused by mechanical problems or complicated start-up procedures,

- easier to operate and maintain,

- automatic nitrogen purge feature for enhanced safety. 


\section{Polyethylene Terephthalate (PET) Bottle Separator}

\section{General}

Procedyne Corporation developed a unique combination of various separation processes for the purpose of recycling polyethylene terephthalate (PET) beverage bottles as a spin-off from a separate program involving waste plastics recovery.

\section{History}

To reduce the amount of municipal solid waste disposed of in landfills, the U.S. Environmental Protection Agency (EPA) has encouraged the development of recycling methods. Approximately 7\% of landfills consist of plastics; $55 \%$ of plastic beverage bottles produced in the United States in 1987 consisted of PET soft drink bottles and high-density polyethylene (HDPE) milk and fruit juice containers. The output of the PET beverage bottle recycle system is granulated PET and HDPE plastics separated, washed and dried, and of sufficiently high quality for some important recycle uses.

A demonstration plant separated approximately 20 million $\mathrm{lb}$ of bottles into constituent PET, HDPE, and aluminum. The separator is currently recycling more than 18 million $\mathrm{lb} / \mathrm{yr}$ at a New York Pepsi-Cola plant. The recycled stream consists of about $78 \%$ PET, $20 \%$ HDPE, and between $1.4 \%$ and $1.5 \%$ aluminum, all of which is recycled.

\section{Technology Description}

The recycling process involves conveying collected bottles to granulators, where the bottles are cut into pieces less than three-eighths inch in size; the granulated material is then fed into a paper-removing machine where the paper particles are removed by an air-lift principle. The material is then fed through a chemical purification system for removal of aluminum and separation of the PET from the HDPE, and then repolymerized. Intensive washing then occurs to remove glue, sugar, and other contaminants; the washed PET is then dried and packed for shipment. The washing systems recirculate water to minimize plant effluents to the sewer.

\section{Benefits}

\section{Energy Benefit}

The energy benefit of this technology is shown in Table 4.2 on page 4.4. 


\section{Environmental Benefit}

The most significant benefit of this process is the decrease in the amount of waste deposited in landfills.

\section{Quality Improvements/Technical Advantages}

None identified.

\section{Productivity Improvements}

None identified.

\section{Employment}

None identified.

\section{International Competitiveness}

None identified.

\section{Current Status}

The New York Pepsi-Cola plant had seen an increase in the recovered amount of PET by the separator in the early 1990s because of increased recycling efforts. Procedyne has not installed any other units, however, because other systems have been developed and installed by other companies, independent of their initial design.

Demand for recovered PET has been limited in the past by restrictions on potential uses of recycled plastic. Potential uses have increased, however, including a new beverage bottle design using recycled PET as a reinforced cup/base at the bottom of bottles.

The company that operated the bottle separator at the New York Pepsi-Cola plant went out of business in 1993. This technology is in use at many locations in the United States but in different forms and different systems than originally developed. Because the demonstration plant is no longer operating, this technology can no longer be tracked. 


\section{Plating Waste Concentrator}

\section{General}

LICON, Inc., developed an energy-efficient vapor concentrator/compressor and a heat pump evaporator for the electroplating industry.

\section{History}

Discharge of rinse water containing hazardous chemicals in the electroplating industry contributes to water pollution control problems and a loss of chemicals. The system that has been designed by LICON reduces the volume of liquid waste and is a more efficient process than simple, heat-driven evaporation. In addition, some of the spent plating chemicals can be recycled if the temperature of the bath is kept below $4^{\circ} \mathrm{C}$ to minimize chemical breakdown. A freon heat pump evaporator was also developed to operate at lower temperatures and was tested to ensure that it could be used to recover cadmium cyanide.

\section{Technology Description}

The waste concentrator system consists of a vapor-recompression evaporator coupled to a single-effect evaporator that uses waste heat as an energy source. The two evaporators complement one another for maximum production with minimum energy input. Evaporation occurs at about $60^{\circ} \mathrm{C}$ in the vapor recompression evaporator and at about $50^{\circ} \mathrm{C}$ in the waste heat evaporator.

The heat pump evaporation system uses a vacuum evaporator with a water-to-water heat pump incorporated into the design. The design includes a freon heat pump that heats water, which is fed to the evaporator. There, the water is used to boil rinse water in a vacuum. The freon is heated by water from the condenser and by compression. The system includes a freon crystallizer used to chill and remove carbonate crystals from the solution.

The vapor-recompression evaporator is very energy efficient. Its energy efficiency is equivalent to that of a conventional 10- to 12-effect evaporation system. The energy in the latent heat of evaporation is recycled by the compressor. 


\section{Benefits}

\section{Energy Benefit}

The energy benefit of this technology is shown in Table 4.2 on page 4.4 .

\section{Environmental Benefit}

The environmental benefits of this technology include a decrease in the energy requirements to evaporate water, a large reduction in cooling water requirements, a significant decrease in the amount of harmful chemical discharges in rinse water, and an increase in the amount of water and chemicals that are recycled.

The environmental benefits are recycled wastewaters, recovery of solvents and chemicals, volume reduction of hazardous wastewaters, and a decrease in the amount of steam or electricity required over conventional single-effect evaporators.

\section{Quality Improvements/Technical Advantages}

Better rinsing with higher quality distilled water.

\section{Productivity Improvements}

More throughput is possible with less haul away pollution, which in turn lowers costs associated with U.S. Environmental Protection Agency (EPA) compliance.

\section{Employment}

No significant impact. On occasion, larger companies will hire operators for the equipment.

\section{International Competitiveness}

Two units have been sold overseas, one of which is still operating.

\section{Current Status}

A variety of efficient evaporative concentrators are available from LICON that can handle a wide range of applications, depending on the type and amount of waste or process stream that is to be treated and the energy available at the treatment site. 
Eight units were sold in FY 1993, and one unit was decommissioned, resulting in a total of 64 units currently in operation in the United States. To date, two units have been sold overseas, one of which is still in operation.

Barriers to the commercialization of this technology have included long lead times for projects and the large capital investment for many companies. An environmental tax credit or low-interest loans would help motivate companies to use recycle technology.

Low-temperature boiling, the broadest line of evaporators with the lowest operating costs, custom designs, capital cost recovery (haul-away savings), and water and chemicals recycling have been this technology's strongest selling points. In areas of the country that do not have sewers or refuse to accept hazardous waste as a liquid, there is a strong impetus to use this technology, as well as in areas of the country (e.g., California) that encourage water recycling. 


\section{Reclaim and Reuse Wastewater}

\section{General}

This project's goal is to clean the rinse wastewater used in painting to the point where it can be reused. Currently the waste water is shipped a substantial distance and disposed of as hazardous waste. Modifications are required both to the treatment process and to the paint cleaner system to incorporate the recycle process. The reclaimed water contains impurities at a low enough concentration that it can be reused and the impurities actually increase the cleaning effectiveness of the system. Therefore, the water can be piped from the holding tank back to the various manufacturing areas for reuse.

\section{History}

PPG Industry's Cleveland plant manufactures coatings for the automobile industry. Some products are water-based coatings, as opposed to solvent-based products, to ensure product quality. Processing equipment for the water-based products is frequently cleaned with water. This generates thousands of gallons of wastewater, which is now disposed of as hazardous waste by transporting it to a state-licensed incinerator.

\section{Technology Description}

The reclaim and reuse waste water system was developed by Ohio and PPG Industries for the purpose of limiting the amount of waste water that is disposed of as hazardous waste. The water-based coating waste water would be collected separately from the other wastes and routed to a new separation system. A nonthermal, nonvaporization physical separation system recovers the water from the paint waste water. The recovered water is pumped to a holding tank. The recovered water still has some ketones and other impurities in low concentration, but this is beneficial because, based on preliminary tests, the recovered water cleans the equipment better. The reduced volume of waste is then collected for disposal.

\section{Benefits}

\section{Energy}

No energy impact of this technology has been identified. 


\section{Environmental}

The project is expected to reduce annual generation of contaminated water at the plant from 400,000 gal to 20,000 gal. Air emission savings will also be achieved be reducing the number of 350 -mile tanker trips to the hazardous waste energy recovery facility. In the past, 65 trips were made per year; with the new system, only four trips are required. The energy recovery facility will as also reduce emissions by not having to incinerate the 400,000 gal of wastewater.

\section{Quality}

No quality impact of this technology has been identified.

\section{Productivity}

No productivity impact of this technology has been identified.

\section{Labor}

No labor impact of this technology has been identified.

\section{Current Status}

To date, PPG Industries has installed one unit and has no plans to commercialize or install additional units. 


\section{Recuperators}

\section{General}

General Telephone and Electronics (GTE) has developed a ceramic recuperator capable of withstanding high furnace exhaust temperatures. As furnace exhaust gases pass through the ceramic recuperator, the ceramic matrix is heated. Cool air is simultaneously passed through the recuperator in adjacent channels to the exhaust for preheating before it reaches the furnace burners. By preheating the air in the recuperator, the cost of heating makeup air for the furnace can be reduced by as much as $40 \%$. The higher the temperature of the furnace exhaust gases, the greater the potential for energy savings.

\section{History}

The DOE assisted in the development of ceramic recuperators through a cost-sharing program with GTE. DOE's participation enabled energy savings to be documented, industry acceptance of recuperators to be accepted, and credibility of ceramic recuperation to be added. GTE now markets four recuperator sizes: $300,000 \mathrm{Btu} / \mathrm{h}, 600,000 \mathrm{Btu} / \mathrm{h}, 1 \mathrm{MMBtu} / \mathrm{h}$, and 1.5 MMBtu/h. Coors Porcelain also markets a similar, compact, matrix-type, ceramic recuperator.

\section{Technology Description}

Up to $67 \%$ of the energy generated during industrial combustion processes is lost in furnace exhaust gases. Heat recuperators can be employed to recover some of this otherwise wasted energy. The recuperator transfers heat from the exhaust gas stream to the incoming combustion air. As a result of preheating the incoming air, the amount of fuel required to raise the air temperature to combustion levels is reduced by $20 \%$ to $30 \%$ for the most effective conventional (metal) recuperators.

Conventional recuperators are typically constructed from a sheet of metal in a plate, tubular, or finned design. These recuperators suffer from their susceptibility to damage at temperatures in excess of $1500^{\circ} \mathrm{F}$. At these high temperatures, the resistivity of the metal to corrosion is significantly reduced. At high temperatures, metal recuperators can be deformed by the thermal stresses resulting from the normal temperature changes that take place in industrial processes. This deformation can result in fracturing and joint failure.

In recent years, the structural integrity of ceramic materials has sufficiently improved to allow their substitution for traditional recuperators, thus largely overcoming the temperature and corrosion resistivity limitations associated with metal. Typical ceramic recuperators are constructed in either of two general configurations. The first type of recuperator consists of a square block through which cool inlet air and 
hot exhaust air flow on alternating layers. A second type of recuperator exists in which cool inlet air and hot exhaust air pass through coaxial tubes. With both configurations, is while the exhaust gases are cooled in the recuperator, the inlet air is preheated and fed into the furnace.

Ceramic recuperators can be easily installed in a new plant or can be retrofitted to an existing furnace. Their compact size facilitates their installation close to the furnace burners, which is a position offering the hottest flue gases and, hence, the greatest thermal efficiency.

Recuperators are available in sizes ranging from less than $300,000 \mathrm{Btu} / \mathrm{hr}$ to many millions of $\mathrm{Btu} / \mathrm{hr}$ per unit. As many individual recuperator units may be employed simultaneously at a single site, and the upper limit for furnace heat output is virtually unconstrained.

\section{Benefits}

\section{Energy Benefit}

The energy benefit of this technology is shown in Table 4.2 on page 4.4.

\section{Environmental Benefit}

The use of ceramic recuperators reduces the amount of emissions from the metals processing industry by decreasing the overall quantity of fuel required for heat treating and forging.

\section{Quality Improvements/Technical Advantages}

None identified.

\section{Productivity Improvements}

None identified.

\section{Labor Improvements}

None identified.

\section{Current Status}

GTE could not be contacted during 1993. Energy savings figures from 1992 have been used for 1993 . 


\section{Reverse Brayton Cycle Solvent Recovery}

\section{General}

A project researching the capture and recycling of volatile organic compounds (VOCs) and chlorofluorocarbons (CFCs) has developed a reverse Brayton cycle system. Solvent use in most industrial applications results in VOC emissions to the atmosphere. Some examples of industrial processes in which VOC emissions are prevalent are coating processes, tape and film manufacture, textile manufacture, printing processes, hydrocarbon production and distribution, wood composites, and plastic foams.

Industry is presented with the need to control the VOC emission by capturing and recycling it back to liquid solvent. Solvents can require up to $30,000 \mathrm{Btu} / \mathrm{lb}$ to be manufactured when considering both chemical energy of the feedstock and processing energy requirements. Loss of solvents to the environment result in loss of embodied energy since additional solvents must be manufactured. In addition, energy is typically required to meet emissions criteria imposed by environmental regulations.

\section{History}

The Brayton cycle solvent recovery heat pump (BCSRHP) project was sponsored by the DOE Office of Industrial Programs in cooperation with the 3M Company. Two units had been developed and were operational at $3 \mathrm{M}$ at that time. Both of these systems employed a reverse Brayton cycle as a means of condensation. This project stemmed from the DOE's identification in the 1970 s of solvent recovery and recycling as a means for significant nation-wide energy conservation.

\section{Technology Description}

In 1980, approximately 19.3 million tons of volatile organic solvents were lost as waste emissions from industrial processes of the petroleum, organic chemicals, paint, adhesive, printing, and dry-cleaning industries. The Brayton cycle heat pump recovers volatile organic solvents from these waste emissions. With this system, solvent-laden gas enters the Brayton cycle compressor, where part of the heat of compression drives the turbines, augmenting the electrical energy supplied to the motor-driven compressor. The rest of the heat of compression is returned, via a regenerator, for reuse in the industrial process. Solvent precipitation begins in the condenser and continues as the gas mixture expands through the turbine. Expansion of the gas causes further condensation of the solvent, which is collected in a coalesce separator. 


\section{Benefits}

\section{Energy Benefit}

The energy benefit of this technology is shown in Table 4.2 on page 4.4.

\section{Environmental Benefit}

The application of this technology results in a direct environmental benefit in that the VOCs that would have been released as emissions are recaptured. This technology also results in an indirect environmental benefit through the energy savings resulting from reusing these compounds that are very energy intensive to produce. This production of this energy would have resulted in the production of $\mathrm{SO}_{\mathrm{x}}, \mathrm{NO}_{\mathrm{x}}$, and $\mathrm{CO}_{2}$ gases, each of which has a detrimental impact to the environment.

\section{Quality Improvements/Technical Advantages}

None identified.

\section{Productivity Improvements}

None identified.

\section{Labor Improvements}

None identified.

\section{International Competitiveness}

None identified.

\section{Current Status}

The contact could not be reached this year. All units in operation last year will be assumed to still be in operation. 


\section{Slot Forge Furnace and Recuperator}

\section{General}

Hague International contracted with DOE in 1978 to produce a high-temperature, ceramic shelland-tube recuperator suitable for recovering exhaust heat from furnaces in the metals fabrication industries. Hague also constructed a slot forge furnace designed with the recuperator, although the recuperator could also be used as a retrofit to existing furnaces.

\section{History}

According to Hague personnel, the project was the first to apply ceramics in the area of heat exchange and recovery. Hague had filed for patents for their design prior to DOE involvement but had not constructed a system. After initial prototype development, DOE funded a second effort to help cover capital and maintenance expenses for demonstrations in 27 plants in the United States. Many of the plants chose to retrofit existing furnaces with the recuperator rather than to install the entire slot forge furnace system.

Recuperator maintenance costs in some installations have caused users to eliminate or replace the recuperator. Many of the ceramic tubes have been replaced with improved tubes from other manufacturers.

\section{Technology Description}

The high-performance slot forge furnace design retained the simplicity of conventional slot furnaces while adding such energy-conserving modifications as recirculation burners, improved temperature controls, air/fuel ratio controls, and lightweight furnace wall insulation that reduces the thermal mass and furnace heat-up times and prevents heat conduction losses. The key addition, however, is the ceramic recuperator that heats incoming combustion air with furnace exit gases. This silicon carbide recuperator can recover $45 \%$ to $55 \%$ of the heat energy from the $2,400^{\circ} \mathrm{F}$ to $2,700^{\circ} \mathrm{F}$ exhaust gases, using it to preheat the incoming combustion air to about $1,500^{\circ} \mathrm{C}$.

\section{Benefits}

\section{Energy Benefit}

The energy benefit of this technology is shown in Table 4.2 on page 4.4 . 


\section{Environmental Benefit}

Through the application of the recuperator, energy is extracted and heat is recycled, which reduces the amount of fuel used and the amount of gas particles emitted into the air. When operated at a high utilization rate, the new slot forge furnace consumes about $900 \mathrm{Btu}$ of fuel per pound of steel, compared with the 5,000 to $15,000 \mathrm{Btu} / \mathrm{lb}$ used by conventional slot furnaces.

\section{Quality Improvements/Technical Advantages}

This technology results in less oxidation of metallic materials being heated.

\section{Productivity Improvements}

There is an improved ability to heat more pounds of metal per Btu, and there is less oxidation of metal being heated, resulting in a higher yield.

\section{Employment}

No benefit has been identified.

\section{International Competitiveness}

None identified.

\section{Current Status}

Energy estimates reflect the savings of units installed for hot steel forging and aluminum melting operations. Energy savings for units that were sold prior to 1983 can be found in Table 4.3. Hague has not sold any slot forge furnaces for some time. All of the more recent sales have been recuperators used to retrofit older furnaces. Some furnaces have begun to be phased out of operation because newer recuperators are more reliable (although not necessarily more efficient).

- Hague reported 36 units currently operating (four of which have been transferred to Table 4.3).

- No recuperators were sold and two were decommissioned by Hague during FY 1993.

- Hague reported four overseas sales to date (all to Japan). 
- Two of the seven companies that had units installed and were contacted annually went out of business. The remaining five companies reported their units operating at the same schedules reported last year.

A barrier to the sale of this technology has been this industry's lack of interest in saving energy (which is not a high priority). On the other hand, the reduction in energy consumption offered by this technology remains as its strongest selling point, once the monetary impact of the energy savings potential is explained. 


\section{Solar Detoxification}

\section{General}

Solar detoxification refers to a family of technologies that employ solar energy to detoxify a variety of toxic organic and inorganic substances.

\section{History}

Solar detoxification, funded by DOE, has been researched by the Solar Energy Research Institute (NREL) and the University of Dayton. NREL and Sandia National Laboratories will be joining efforts to meet a five-year DOE initiative to propel this technology from the laboratory to the marketplace. The DOE initiative calls for strong industry involvement with the development of the process to facilitate the transfer of the technology through hands-on research, testing, workshops, conferences, and demonstrations.

\section{Technology Description}

Solar detoxification is a DOE-funded project investigating the promising capabilities of sunlight to detoxify hazardous wastes in the environment. One process employs a semiconductor catalyst that absorbs high-energy photons to attract oxygen in contaminated water. This oxygen facilitates the formation of reactive chemicals that break down the wastes into treatable nontoxic products, such as carbon dioxide and dilute hydrogen chloride. This process enables the wastes to be handled onsite in a single process, eliminating transfer of the wastes elsewhere, as well as limiting the site operator's liability for onsite operations. Chemicals that have been successfully detoxified include trichloroethylene, a carcinogenic solvent commonly found in drinking water; direct Red No. 79, a textile dye; and pinkwater, a waste from munitions production. A second process employs concentrated sunlight to photolytically break down hazardous substances into simpler, nonhazardous products at lower temperatures and with much less carbon dioxide than with conventional incineration. This process employs sunlight concentrated 1,000 times to temperatures up to $1,000^{\circ} \mathrm{C}$ to first heat the wastes (using infrared frequency light) and then to break the chemical bonds and destroy the molecules (using light in the ultraviolet frequency range).

\section{Benefits}

\section{Energy Benefit}

The energy benefit of this technology is shown in Table 4.2 on page 4.4 . 


\section{Environmental}

Beyond cost benefits, solar detoxification offers several environmental benefits to potential users of the technology. Because the process is destructive, the organic compounds are treated only once. This treatment takes place on site as opposed to other technologies such as air stripping or granular activated carbon (GAC). In the case of air stripping, the hazardous organic compounds are simply transferred to the atmosphere. GAC involves transferring the material to an offsite landfill or treatment facility for incineration. Use of the solar technology should, therefore, result in a cleaner environment, lower treatment costs, and lower user liability.

\section{Quality}

The primary quality improvement is the treatment of air stream wastewater at lower costs than offered by conventional treatment systems.

\section{Productivity}

Productivity improvements are highly dependent on the application of the technology. For remediation applications, the technology will result in increased volumes of treated water or air for a given cost. For processes such as paint booths or dry cleaning where quantities of organic compounds are often regulated based on monthly or yearly discharge limits, use of the solar detoxification technology may result in significant improvements in productivity. For some cases, this may be the difference between closing down a process or continuing operation.

\section{Labor}

A recent study by DOE projected a total of seven new jobs created by this technology by 1994 and a total of 1,248 new jobs created by this technology by the year 2010 .

\section{Current Status}

No commercial units are currently operating (as of the end of 1993). However, both ClearFlow and International Technology (IT) Corporation have designed and fabricated mobile pilot-scale units for use in performing onsite treatability tests using the water and gas phase photocatalytic processes. The onsite tests are necessary to provide adequate system information for scale-up to a commercial unit.

No commercial units have been installed. The National Renewable Energy Laboratory (NREL) completed operation of a pilot-scale system at Tyndall Air Force Base in Florida for the water-phase process. ClearFlow completed operation of a pilot-scale system at a contaminated groundwater site in Colorado. IT Corporation recently completed a pilot test of its gas phase process at March Air Force Base in California. 
Two pilot-scale systems have been decommissioned. The original pilot-scale system located at Lawrence Livermore National Laboratory was moved to Tyndall Air Force Base to investigate the use of the technology for treating contaminated groundwater. This system was recently removed from Tyndall and is currently located at NREL.

IT Corporation, ClearFlow, and Solar Kinetics are interested in commercializing the technology because of the potential economic benefits to their companies. Both the water-phase and gas-phase technologies are projected to have lower costs than conventional technologies for some applications. In particular, ClearFlow has focused its marketing efforts on recycling industrial wastewater because of the technology's unique ability to simultaneously oxidize organic compounds and reduce metals contained in the water. Recent studies indicate that the gas-phase process may result in even greater cost savings over conventional technologies.

As this technology has not yet generated significant energy savings, it will stay on the emerging technology table this year and will be tracked for future energy savings. 


\section{Solvent Recovery From Effluent Streams}

\section{General}

Membrane Technology \& Research, Inc. (MTR), received DOE funding to develop a system to recover solvent from an industrial air stream. This system stems from an effort to recover sensible heat and organic solvents from air streams of drying ovens using a membrane separation concept.

\section{History}

Many industrial processes exhaust hot air streams containing low concentrations of organic solvents. Many of these streams are produced in high-temperature industrial ovens where, because of the explosion danger, strict limits govern the concentration of solvent vapors. To adhere to these regulations, streams are commonly ventilated in the oven chamber with fresh air in sufficient volumes to dilute the maximum vapor concentration to acceptably safe levels. This method wastes large amounts of energy because dilution of vapor streams lowers the temperature to a point where their energy cannot be recovered economically.

\section{Technology Description}

In MTR's system, a contaminated air stream is introduced into an array of membrane modules. Organic solvents are preferentially drawn through the membrane by a vacuum pump. The solvent is condensed and removed as a liquid. Transport through the membrane is induced by maintaining the vapor pressure on the permeate side of the membrane of the air stream containing $0.01 \%$ to $5 \%$ organic solvent. The process is particularly economical for recovering hydrocarbon vapors and chlorinated and halogenated hydrocarbons.

\section{Benefits}

\section{Energy Benefit}

The energy benefit of this technology is shown in Table 4.2 on page 4.4. 


\section{Environmental}

The environmental benefit of this technology is a direct one, as the technology recovers environmentally harmful solvents from waste streams before they can enter the environment. Additionally, the emissions $\left(\mathrm{SO}_{x}, \mathrm{NO}_{x}\right.$, and $\mathrm{CO}_{2}$ ) that would result from the production of the energy required to make these solvents are also prevented from entering the environment.

VaporSep can virtually eliminate atmospheric emissions of volatile organic compounds (VOCs), many of which deplete the stratospheric ozone layer, promote global warming, or are toxic. By achieving VOC removal and recovery efficiencies of up to $99.99 \%$, VaporSep allows the end user to comply with environmental regulations related to these pollutants.

This technology saves resources by recovering valuable solvents, hydrocarbons, and other VOCs that would otherwise be lost to the atmosphere. By contrast, incineration destroys these valuable resources; it also uses large amounts of energy and can pollute the air. Compared with condensation as a recovery technique, VaporSep achieves higher recovery rates or equivalent recovery rates under less extreme (recovery-intensive) temperature and pressure. The energy savings offered by VaporSep for the recovery of highly volatile compounds can be considered an environmental benefit because electricity generation can result in air pollution.

VaporSep does not create secondary waste problems. By contrast, carbon adsorption, another conventional VOC recovery technique, produces spent carbon that must be regenerated with steam and ultimately disposed of as hazardous waste. Furthermore, the carbon regeneration step requires energy to produce the steam; if electricity is used, the regeneration step indirectly contributes to air pollution because electricity generation usually produces air pollution. VaporSep, on the other hand, recovers VOCs in immediately reusable form, without a steam regeneration step.

\section{Quality Improvements/Technical Advantages}

Compared with condensation, VaporSep membrane technology offers superior recovery performance by achieving far higher recovery rates or achieving comparable recovery rates under less rigorous temperature and pressure conditions. Many VOCs, such as chlorofluorocarbons (CFCs) and other halogenated hydrocarbons, are difficult to remove by condensation because they are highly volatile and streams containing them cannot be brought to their dew point without excessive cooling. By combining membrane separation with condensation, the VaporSep system eliminates the need for extremely low temperatures and, hence, the problems encountered in low-temperature condensation. These problems include the need to use a two-stage chiller, the high-energy cost of maintaining low temperatures, and condenser icing with streams; VaporSep can accommodate lower feed stream concentrations because its recycle system design serves as an internal preconcentrating device.

Compared with incineration, VaporSep uses far less energy and is a nondestructive technology that recovers valuable resources. Incineration eliminates VOC emissions by destroying the VOCs, sometimes 
polluting the air in the process. Some CFCs and other halogenated compounds are not good candidates for incineration because they are nonflammable.

Compared with carbon adsorption, VaporSep offers many advantages, including the fact that it does not create secondary waste streams. Carbon adsorption produces spent carbon, which must be regenerated and ultimately disposed of as hazardous waste. Offsite carbon regeneration and disposal are extremely expensive options, because regeneration alone can cost, in the case of CFCs, $\$ 20$ to $\$ 40$ per pound of material recovered. The VaporSep system, on the other hand, is usually very economical for CFC and other VOC recovery applications, with payback occurring in a few months in many cases.

VaporSep recovers CFCs in immediately reusable form. Carbon adsorption requires a stream regeneration step to release the CFCs for collection. Furthermore, most halogenated solvents are unstable during the steam regeneration cycle, producing hydrochloric acid, which corrodes the system, and some low-boiling compounds are not adequately absorbed.

VaporSep is suitable for a wider range of VOC concentrations. Carbon adsorption can only be used efficiently for very diluted streams because the operating and capital costs of the plants increase with increasing solvent concentration in the feed. High concentration also leads to unacceptably high temperatures in the carbon bed, as carbon abortion is an exothermic process. Consequently, process streams being treated by carbon abortion frequently must be diluted before being passed to the carbon beds. VaporSep units are smaller and more mobile than carbon adsorption systems of similar capacity; they are more easily integrated into existing processes.

Finally, VaporSep has been demonstrated as an equally effective recovery method for CFCs and CFC replacement compounds, such as HCFC-123. Carbon-based adsorbents for the HCFC and HFC compounds are not readily available.

\section{Productivity Improvements}

Compared with incineration, condensation, and carbon adsorption, Vaporsep produces a higher yield of recovered VOC, which can be recycled or reused for savings in raw materials costs. VaporSep systems are easier to install, start up, operate, and maintain than condensation and carbon adsorption systems, resulting in increased worker productivity.

\section{Employment}

Commercialization of this technology has created new employment at MTR. The company has added 10 new positions in the last year (a 38\% increase over the previous year) in research and development, engineering, marketing, manufacturing, and administration. Successful commercialization of new applications for this technology could result in additional manufacturing jobs at those outside fabricators MTR may choose to work with. 


\section{International Competitiveness}

None identified.

\section{Current Status}

MTR is producing medium-sized units under the trade name of VaporSep. There are currently 18 units operating. Thirteen units were installed since September 1992; none of these were sold overseas.

\begin{tabular}{lc}
\multicolumn{1}{c}{ Location } & Flow Rate (SCFM) \\
\cline { 2 - 2 } Arkansas & 20 \\
Texas & 10 \\
Texas & 4 \\
Minnesota & 4 \\
Minnesota & 2 \\
California & 10 \\
Oklahoma & 4 \\
Minnesota & 4 \\
California & 2 \\
Texas & 4 \\
Puerto Rico & 2 \\
California & 1 \\
Pennsylvania &
\end{tabular}

Barriers to the adoption of this technology include hesitation on the part of conservative businesses to buy a new technology, poor business climate, insufficient funds to support product launch and other essential marketing activities, and slow implementation of the Clean Air Act.

The strongest selling points of this technology have been the following:

- VaporSep recovers VOCs from air with extremely high efficiency, usually at a fraction of the cost of acquiring the virgin compounds. 
- VaporSep can virtually eliminate VOC emissions.

- Payback on a customer's investment in capital equipment can occur in as little as a few month's time.

- Other advantages over alternative techniques for VOC control are strong selling points in individual situations. 


\section{Variable Frequency Microwave Furnace}

\section{General}

Researchers at Oak Ridge National Laboratory (ORNL) have participated with Microwave Laboratories (a private company in New Jersey) in the development of a variable-frequency microwave furnace with potential industrial applications. The furnace can be used in the processing of certain materials such as ceramics or materials, requiring plasma coating, and in a number of other industries and sectors as well.

\section{History}

Microwave Laboratories has been in the radar-jamming business for a number of years. ORNL researchers first developed the idea of a variable-frequency microwave as a solution to difficulties encountered in the sintering of ceramics and in other processes. The principal conceptual difficulty lay in discovering what could be used as a high-power source for the microwaves. Microwave Laboratories had an existing technology that could be, and was, adapted to this new application. ORNL and Microwave Laboratories are working closely in the development of this device, with ORNL contributing materials, materials processing, and theoretical expertise.

\section{Technology Description}

Conventional microwave ovens operate at a fixed frequency that results in the optimal transfer of power to water (found in most foods). The new microwave furnace typically provides from $1 \mathrm{~kW}$ to $5 \mathrm{~kW}$ at frequencies that vary between 4 and $8 \mathrm{GHz}$. The varying of the frequency is accomplished through the use of a standard, low-power signal amplified by a traveling wave tube (developed initially for radarjamming applications). The use of this varying frequency eliminates "hot" and "cold" spots found in conventional microwaves and generates superior power transfer. This type of microwave enables the heating of certain metallic and other materials that could not be heated in conventional, fixed-frequency microwaves because of energy reflection.

The primary energy benefit of this technology stems from the improved power transfer capabilities of the furnace. By varying the frequency, the operator can tune the oven for maximum power transfer, resulting in the most efficient heating and/or treating of the material in the oven. As the material heats, this optimal frequency for power transfer typically changes. The oven can change operating frequency to match this power change. 
The oven may also be operated to continuously scan a wide range of frequencies. In addition to eliminating hot and cold spots, power transfer occurs more efficiently with respect to conventional ovens. This stems from the fact that power will automatically transfer to the material in the oven at those frequencies at which it most efficiently couples. Power at other frequencies is not transferred and, hence, is not consumed by the furnace.

\section{Benefits}

\section{Energy Benefit}

The energy benefit of this technology is shown in Table 4.2 on page 4.4 .

\section{Environmental}

In addition to the reduced emissions resulting indirectly from the energy savings discussed above, this technology has direct environmental benefits as well, depending on its application. Testing is currently under way to employ the furnace in the destruction of volatile organic compounds in soils. The use of the technology for this application is more efficient and produces fewer environmentally harmful by-products than competing technologies. In one application, the furnace can be employed to cure resins found in carpet backing. This technique allows the use of less toxic resins that can cure by the molecular agitation caused by microwave energy rather than by molecular activity (activated by chemical reaction to another toxic chemical).

\section{Quality}

The unique properties of the variable-frequency furnace allow novel materials processing techniques to be employed. This oven, for instance, allows ceramics to be cured by microwave energy in a uniform manner (rather from the outside in, through the use of conventional ovens), by operating the oven at a frequency optimally suited to the transfer of power to these materials. Certain metals that cannot be treated in conventional microwave ovens due to energy reflectance can be treated by this technology.

\section{Productivity}

The improved power transfer characteristics of the furnace allow for faster processing times. In the carpet application mentioned above, the curing of the backing is currently the limiting step in carpet production. The use of this technology would greatly speed up this step, resulting in much higher productivity and less energy consumption per unit of carpet produced. 


\section{Labor}

No labor impact of this technology has been identified.

\section{International Competitiveness}

None identified.

\section{Current Status}

A number of units have been sold by late 1993. It is too early to determine reliable energy saving estimates; these estimates will be made in 1994. At the present time, this technology will remain on the emerging technology table. 


\section{Waste Energy Recovery at Honolulu, Hawaii}

\section{General}

The City and County of Honolulu developed and built a waste-to-energy plant. This plant takes in mixed waste and burns it to produce electricity. Such a system could be installed in any area that has proper types of waste and a shortage of electricity.

\section{History}

The DOE contracted for a report which was produced in October 1982, titled Evaluation of Technical Proposals for Honolulu Program of Waste Energy Recovery. As a result of this report, DOE and the City and County of Honolulu decided to build a waste-to-energy plant. This plant began full operation in November 1989.

\section{Technology Description}

Waste is received at the plant and is then sorted by categories. Some of the waste is sent to a landfill or another type of approved disposal method. The remaining waste is then processed and burned to produce steam, which in turn is used to produce electricity. All environmental standards are complied with, and the waste from the burning is either burned again or sent to an appropriate disposal site. The electricity that is produced is sold to the local utility.

\section{Benefits}

\section{Energy Benefit}

The energy benefit of this technology is shown in Table 4.2 on page 4.4 .

The energy benefits are quite substantial, and this project produces electricity for the local area utility. Waste is burned to produce steam, which then turns a turbine and produces $373,508,000 \mathrm{kWh}$ of power. The net to the utility is $327,600,000 \mathrm{kWh}$, the plant uses $45,908,000 \mathrm{kWh} / \mathrm{yr}$ in production. 


\section{Environmental}

There are many environmental benefits. First, this technology cuts down on the amount of waste placed in landfills. Second, this technology produces electricity which would have to be produced by other means, such as building a coal fired, gas, or nuclear facility. The plant also conforms to all environmental standards and conserves natural resources.

\section{Quality}

No quality impact of this technology has been identified.

\section{Productivity}

No productivity impact of this technology has been identified.

\section{Labor}

No labor impact of this technology has been identified.

\section{International Competitiveness}

None identified.

\section{Current Status}

Only one unit has been in operation since 1989; none are expected to be constructed in the near future. This technology has been added to Table 4.2, with the savings shown being retroactive to 1990 (the first year the plant was in full operation). 


\section{Distribution}

No. of

Copies

\section{OFFSITE}

12 DOE/Office of Scientific and Technical Information

2 Energetics Inc.

7164 Gateway Drive

Columbia, MD 21046

ATTN: Nancy Margolis

Aziz Azimi

N. K. Cole, Budget Analyst

U.S. Department of Energy

Office of Industrial Technologies

Room 6B-052, EE-20

1000 Independence Ave., SW

Washington, DC 20585

2 U.S. Department of Energy

Office of Waste Reduction Technology

Room 5G-067, EE-22

1000 Independence Ave., S.W.

Washington, DC 20585

ATTN: K. D. Sisson

E. Beyma

6 U.S. Department of Energy

Industrial Energy Efficiency Division

Room 5F-035, EE-221

1000 Independence Ave., S.W.

Washington, DC 20585

ATTN: K. D. Sisson

R. C. Jain

W. P. Parks

S. L. Richlen

P. E. Scheihlng

G. Varga
No. of

Copies

13 U.S. Department of Energy

Waste Material Management Division

Room 5F-043, EE-222

1000 Independence Ave., SW

Washington, DC 20585

ATTN: T. L. Johnson

C. Carwile

H. B. Cranford

T. Foust

S. Friedrich

D. Gish

S. Leonard

S. L. Natof

C. Russomanno

A. C. Schroeder

M. Smith

F. W. Wilkins

$5 \quad$ U.S. Department of Energy

Implementation and Deployment Division

Room 6H-034, EE-223

1000 Independence Ave., S.W.

Washington, DC 20585

ATTN: J. Duane

C. J. Glaser

A. Klein

M. L. Quinn

L. Ambs

2 U.S. Department of Energy

Office of Industrial Processes

Room 5F-059, EE-23

1000 Independence Ave., S.W.

Washington, DC 20585

ATTN: P. H. Salmon-Cox

L. Dudley

Distr.1 
No. of

Copies

$4 \quad$ U.S. Department of Energy Advanced Industrial Concepts Division Room 5F-059, EE-232 1000 Independence Ave., S.W.

Washington, DC 20585

ATTN: P. H. Salmon-Cox

D. Boron

E. H. Fu

C. Sorrell

$5 \quad$ U.S. Department of Energy Separations Divison

Room 5F-059, EE-233

1000 Independence Ave., S.W.

Washington, DC 20585

ATTN: D. E Wiley

J. DeWees

L. B. Schilling

S. F. Sobczynski

B. Volintine

5 U.S. Department of Energy

Materials Processing Division

Room 5F-059, EE-234

1000 Independence Ave., S.W.

Washington, DC 20585

ATTN: M. J. McMonigle

G. N. Jagtiani

D. Kaempf

W. A. Obenchain

D. M. Pellish

\section{ONSITE}

U.S. Department of Energy, Richland Operations Office

D. K. Jones

65 Pacific Northwest Laboratory

D. R. Brown

K8-18

L. L. Fassbender

K8-18

B. A. Garrett

K8-09

K. R. Hughes

$\mathrm{K} 8-18$

N. L. Moore (50)

K8-04

J. M. Roop

K8-17

E. J. Stenehjem

K8-04

D. L. Stiles

K8-18

S. C. Weiner

I. L. White

BWO

BWO

Publication Coordination

Technical Publications (5) 